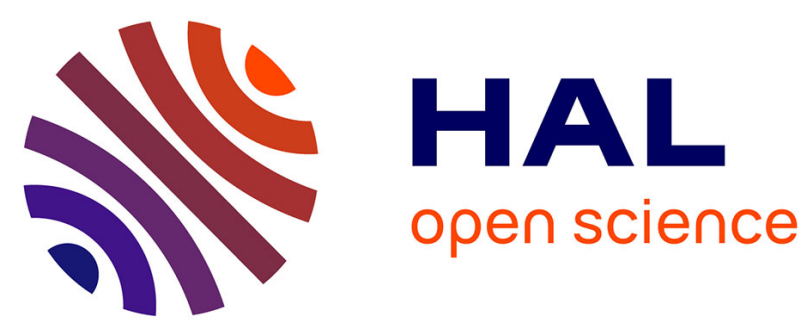

\title{
Effect of supplementary cementitious materials on carbonation of cement pastes.
}

Mickael Saillio, Véronique Baroghel Bouny, Sylvain Pradelle, Matthieu Bertin, Julien Vincent, Jean-Baptiste D'espinose de Lacaillerie

\section{- To cite this version:}

Mickael Saillio, Véronique Baroghel Bouny, Sylvain Pradelle, Matthieu Bertin, Julien Vincent, et al.. Effect of supplementary cementitious materials on carbonation of cement pastes.. Cement and Concrete Research, 2021, 142, pp.106358. 10.1016/j.cemconres.2021.106358 . hal-03118018

\section{HAL Id: hal-03118018 \\ https://hal.science/hal-03118018}

Submitted on 21 Jan 2021

HAL is a multi-disciplinary open access archive for the deposit and dissemination of scientific research documents, whether they are published or not. The documents may come from teaching and research institutions in France or abroad, or from public or private research centers.
L'archive ouverte pluridisciplinaire HAL, est destinée au dépôt et à la diffusion de documents scientifiques de niveau recherche, publiés ou non, émanant des établissements d'enseignement et de recherche français ou étrangers, des laboratoires publics ou privés. 


\title{
Effect of supplementary cementitious materials on carbonation of cement pastes.
}

\author{
Mickael Saillio $^{a^{*}}$, Véronique Baroghel-Bouny ${ }^{b}$, Sylvain Pradelle ${ }^{c}$, Matthieu Bertin ${ }^{b}$, Julien \\ Vincent $^{\mathrm{a}}$, Jean-Baptiste d'Espinose de Lacaillerie $^{\mathrm{d}}$ \\ ${ }^{a}$ MAST-CPDM, Univ Gustave Eiffel, IFSTTAR, F-77454 Marne-La-Vallée, France \\ ${ }^{b}$ MAST-FM2D, Univ Gustave Eiffel, IFSTTAR, F-77454 Marne-La-Vallée, France \\ ${ }^{C}$ Ministry for the Ecological and Inclusive Transition, MTES/CGDD/DRI/AST3, F-92055 La Défense, France \\ ${ }^{d}$ Soft Matter Science and Engineering, UMR CNRS 7615, ESPCI Paris, Université PSL, 10 rue Vauquelin, F- \\ 75005 Paris, France
}

\begin{abstract}
Supplementary cementitious materials (SCM) are increasingly used in concrete for economical and environmental reasons. However, the durability of reinforced concretes against, for example, corrosion induced by carbonation varies. Here, the phase assemblage of various cement pastes with/without SCM (slag, fly ash and metakaolin), carbonated in accelerated conditions $\left(1.5 \% \mathrm{CO}_{2}\right.$ and $65 \% \mathrm{RH}$ ) or not, has been investigated by various technics (XRD, TGA/DTA and ${ }^{29} \mathrm{Si}$ as well as ${ }^{27} \mathrm{Al}$ nuclear magnetic resonance spectroscopy) and compared.

Results show that, after carbonation, anhydrous phases are less decalcified than hydrated phases. In cement pastes with slag, most of the calcium remains in the non-hydrated part of the slag. In contrast, the $C-A, S-H$ phase is deeply modified and results show a coupling between $C-A, S-H$ and hydrated aluminate phases during carbonation. In all carbonated materials, these phases tend to become an aluminosilicate gel, a very amorphous/disordered phase, containing less water than the original hydrates.
\end{abstract}

*Corresponding author. Tel.: +33181668734

E-mail address: mickael.saillio@ifsttar.fr

Keywords: Carbonation, SCM, TGA/DTG, MAS NMR spectroscopy, cement paste.

\section{Introduction}

Reinforced concrete structures can be deteriorated as a result of chloride-induced and/or carbonation-induced corrosion of steel rebars [1-5]. In $\mathrm{CO}_{2}$-free environment, the hydrated Portland cement consists of hydrated phases in equilibrium with a pore solution. Under natural conditions of temperature and pressure, the atmospheric gaseous $\mathrm{CO}_{2}$ penetrates in cementitious materials through the pore system where it dissolves into the pore solution to form $\mathrm{H}_{2} \mathrm{CO}_{3}$ which, by dissociation, decreases the $\mathrm{pH}$ of the pore solution [1-8]. Portlandite $\left(\mathrm{Ca}(\mathrm{OH})_{2}\right)$ plays the role of buffer and maintains the $\mathrm{pH}$ of the pore solution at a $\mathrm{pH}$ value of 12.5 by dissolving, releasing adequately $\mathrm{OH}^{-}$ions and eventually precipitating mainly calcite. However, during the carbonation process, it is not only the $\mathrm{Ca}(\mathrm{OH})_{2}$ that is impacted but also the main calcium containing solid hydrates of cement paste, such as the calcium silicate hydrate C-S-H (or C-A,S-H if alumina partially replaces calcium or silica), the trisulfoaluminate AFt (ettringite) and the monosulfoaluminate AFm [81] or similar compounds (monocarboaluminate, hemicarboaluminate,...). The changes in cementitious materials induced by carbonation are particularly significant when the mixture contains supplementary cementitious materials (SCM) [8][12-21]. For example, binders containing slag form less portlandite and have a higher aluminate phases content than OPC binders while still containing 
high amount of unreacted phase even after long water curing times $[8,12]$. Consequently, for a same exposure environment and time, carbonation ingress in these materials is deeper than in OPC binders [8]. The same can be expected for binders with fly ash or metakaolin since they also contain less portlandite than OPC binders as these pozzolanic materials react with a significant part of the portlandite formed by hydration.

We therefore aimed at contrasting the carbonation behavior of cementitious matrixes formulated with SCM or not and at rationalizing the observed differences. Generally, previous studies of cement carbonation have focused on one or two phases (e.g. portlandite and C-S-H) but here, the simultaneous carbonation of all phases (hydrated or not) was considered in order to reveal possible coupling effects. For that purpose, an experimental campaign of characterization and carbonation was carried out on cement pastes with or without SCM. The SCM considered here were GGBS, fly ash (FA) and metakaolin (MK). The phase assemblage, before and after carbonation, was investigated by thermogravimetric analysis and differential thermal analysis (TGA/DTG-DTA), X-ray diffraction (XRD) and ${ }^{29} \mathrm{Si}$ and ${ }^{27} \mathrm{Al}$ magic angle spinning nuclear magnetic resonance (MAS NMR) spectroscopy.

\section{Experimental}

\subsection{Materials}

Various cement pastes were formulated with CEM I, CEM III/A and CEM III/C issued from the same clinker (Lumbres) provided by Lafarge-Holcim. The fly ash (FA) was provided by Surschiste (Hornaing) (EN 450-1, 2012), the metakaolin (MK) by ARGECO. The main constituents of the cements are given in tables 1 and 2 . All mixtures were hydrated with the same water to binder ratio $(\mathrm{w} / \mathrm{b})$ equal to 0.5 . The studied binders were:

- CEM I (OPC with $97 \%$ clinker in mass),

- CEM I + 20\% FA in mass denoted CEM I FA(20\%),

- CEM I + 30\% FA denoted CEM I FA(30\%),

- CEM I + 40\% FA denoted CEM I FA(40\%),

- CEM I + 10\% MK denoted CEM I MK(10\%),

- CEM I + 25\% MK denoted CEM I MK(25\%),

- CEM III/A (with 62\% GGBS) denoted CEM III GGBS(62\%),

- CEM III/C (with 82\% GGBS) denoted CEM III GGBS(82\%).

Table 1: Chemical compositions of the cement and SCM tested (in \%mass) obtained by ICP-AES

\begin{tabular}{|l|l|l|l|l|l|l|l|l|l|l|}
\hline & $\mathrm{CaO}$ & $\mathrm{SiO}_{2}$ & $\mathrm{Fe}_{2} \mathrm{O}_{3}$ & $\mathrm{Al}_{2} \mathrm{O}_{3}$ & $\mathrm{TiO}_{2}$ & $\mathrm{MgO}$ & $\mathrm{Na}_{2} \mathrm{O}$ & $\mathrm{K}_{2} \mathrm{O}$ & $\mathrm{MnO}$ & $\mathrm{SO}_{3}$ \\
\hline CEM I & 62.53 & 19.54 & 2.90 & 4.98 & 0.30 & 0.84 & 0.30 & 0.82 & 0.09 & 2.97 \\
\hline CEM III/A & 49.77 & 29.86 & 1.28 & 8.10 & 0.46 & 4.61 & 0.40 & 0.56 & 0.16 & 2.29 \\
\hline CEM III/C & 45.70 & 32.00 & 1.00 & 9.90 & 0.50 & 5.80 & 0.63 & 0.54 & 0.20 & 2.00 \\
\hline MK & 2.00 & 66.29 & 4.29 & 21.30 & 1.12 & 0.25 & 0.84 & 0.49 & 0.00 & 0.08 \\
\hline FA & 4.30 & 51.59 & 6.58 & 23.78 & 1.03 & 0.49 & 1.09 & 3.05 & 0.11 & 3.05 \\
\hline
\end{tabular}


Table 2: Mineralogical composition of the CEM I clinker from BOGUE calculation (in \%mass)

\begin{tabular}{|l|l|l|l|l|}
\hline & $\mathrm{C}_{3} \mathrm{~S}$ & $\mathrm{C}_{2} \mathrm{~S}$ & $\mathrm{C}_{3} \mathrm{~A}$ & $\mathrm{C}_{4} \mathrm{AF}$ \\
\hline CEM I & 51 & 28 & 10 & 10 \\
\hline
\end{tabular}

Cement pastes were water cured during 365 days. Sound samples (i.e. non-carbonated) will be denoted "Reference samples" (or "Ref samples" in the figures). A particular focus was made on the characterizations of the four specific binders: CEM I, CEM I MK(25\%), CEM I FA(30\%) and CEM III GGBS(62\%).

\subsection{Carbonation process}

Accelerated carbonation tests are often used to carbonate samples in the laboratory as an alternative to natural carbonation which is a much longer process $[9,17]$. Accelerated carbonation tests consist in, after drying, exposing samples to an atmosphere enriched in $\mathrm{CO}_{2}$ at an optimal relative humidity (40-65\%) [18][21]. Different $\mathrm{CO}_{2}$ concentrations can be applied in these accelerated tests. According to [9], a too high $\mathrm{CO}_{2}$ concentration can change the microstructure more than a natural carbonation process would. A concentration inferior to $5 \%$ is thus recommended. The drying process also can produce artifacts. It increases the rate of carbonation ingress but, for example, when performed at a too high temperature, it alters some cementitious phases such as ettringite.

Consequently, the following carbonation protocols were chosen: after 365 days of water curing, slices of cement pastes were cut and left to dry during 3 days at $60^{\circ} \mathrm{C}$. Then the slices were crushed to sizes lower than $5 \mathrm{~mm}$ (checked by sieving). A part of the crushed samples (as "reference samples") was directly tested or preserved in a $\mathrm{CO}_{2}$-free chamber where $\mathrm{CO}_{2}$ is trap by soda lime and with silica gel. The other part was carbonated in a dedicated chamber $\left(1.5 \% \mathrm{CO}_{2}\right.$ and $\left.65 \% \mathrm{RH}\right)$ until a constant mass was reached (around 2 months) and called "TC samples" (TC meaning totally carbonated).

\subsection{Microstructural characterization}

\subsubsection{TGA- DTG}

Thermogravimetric analyses (TGA) and Differential thermogravimetry analyses (DTG) [18] were performed with a simultaneous thermal analyzer by heating from $25^{\circ} \mathrm{C}$ to $1150^{\circ} \mathrm{C}$ with a $25^{\circ} \mathrm{C} / \mathrm{min}$ ramp. These techniques were used here to quantify the water content lost from portlandite on the one hand and from C-S-H and Ettringite on the other hand (noted C-S- $\mathrm{H}+\mathrm{E}$ ), as well as the $\mathrm{CO}_{2}$ content lost by the calcium carbonates in the samples formed during carbonation. With this $\mathrm{CO}_{2}$ content, it is possible to evaluate the dilution effect due to the amount of carbonates bound by the cementitious matrix in carbonated cement pastes. The initial amount of clinker was also obtained by measuring the remaining mass after the last $\mathrm{CO}_{2}$ loss, with the knowledge of cement and SCM proportions for each mixes. The analyses were applied to crushed reference and TC samples. The device used here is a NETZSCH STA 409 coupled with mass spectrometer in order to analyze the outlet gases. 
X-ray diffraction [4] allows to identify the crystallized phases that is the hydrated phases from clinker hydration (e.g. portlandite, monocarboaluminate ...) as well as the phases formed during carbonation (e.g. calcite, vaterite and aragonite) and to estimate their proportions. Such analyses were carried out here on crushed pastes, carbonated or not (TC and Ref samples). The XRD analyses were performed using the PHILIPS PW 3830 diffractometer with the Ka radiation of cobalt ( $40 \mathrm{KV}$ and $30 \mathrm{~mA}$ ). The scan step size of the diffractometer was $0.02^{\circ} / \mathrm{s}$ in the range of $2 \theta$ from 4 and $76^{\circ}$.

\subsubsection{NMR}

NMR spectroscopy [22] gives access, at a local scale, to the immediate environment of a nucleus. ${ }^{27} \mathrm{Al}$ and ${ }^{29} \mathrm{Si}$ nuclei were probed here by the one-pulse MAS (Magical Angle Spinning) technique [22-25]. NMR spectra have been obtained here with a Bruker Avance $500 \mathrm{MHz}$ apparatus (11.7 T magnetic field). For ${ }^{27} \mathrm{AI} N \mathrm{NR}$, parameters were: $\pi / 6$ pulses (to allow quantitative analysis), $14 \mathrm{kHz}$ spinning speed, 280 scans and $10 \mathrm{~s}$ repetition time. For ${ }^{29} \mathrm{Si} \mathrm{NMR}$, parameters were: $\pi / 2,5 \mathrm{kHz}$ spinning speed, 1008 scans and 50 s repetition time.

The coordination of aluminum atoms can be observed by ${ }^{27} \mathrm{AI}$ NMR $[23,24]$. In a cement paste, aluminum in tetrahedral configuration AI(IV) is generally attributed to aluminum substituted for silicon in C-S-H chains and residual anhydrous cement. Aluminum in octahedral $\mathrm{Al}(\mathrm{VI})$ configuration is divided into three components: AFt (Ettringite), AFm and the third aluminum hydrate (TAH) which is, according to Andersen et al. $[25,26]$, an amorphous/disordered aluminum hydroxide or a calcium aluminate hydrate not observable by XRD [25]. The representative resonance of aluminum in AFm phases can hardly distinguish their different forms such as Friedel's salt, monosulfoaluminate, monocarboaluminate phases and Küzel's salt. However, XRD can complement the information provided by NMR and help to identify what are the AFm phases involved. Finally, the attribution of aluminum in pentahedral configuration $\mathrm{Al}(\mathrm{V})$ is still debated but usually assigned to aluminum substituted for calcium in the C-S-H interlayers or present in non-hydrated phases.

${ }^{29} \mathrm{Si}$ MAS NMR spectra allow identification of the different connectivities of silicon tetrahedron in the samples [22,24],[27-29]. In NMR spectroscopy, silicon tetrahedra are designated as $Q^{n}$, where $Q$ represents the silicon tetrahedron bonded to four oxygen atoms and $n$ denotes its connectivity, i.e. the number of other $Q$ units attached to the $\mathrm{SiO}_{4}$ tetrahedron under study. In cement pastes, $Q^{\circ}$ coordination occurs in anhydrous silicates ( $C_{3} S, C_{2} S$ and also GGBS), while $Q^{1}$ and $Q^{2}$ are present in the C-S-H chains. $Q^{3}$ and $Q^{4}$ correspond to cross-linking of the dreierketten chains of C-S-H or to silicon in silica gels as observed in carbonated samples and there is also $Q^{4}$ from anhydrous $F A$. In the presence of $\mathrm{Al}$, others species can be observed such as $Q^{n}(m \mathrm{Al})$, where $m$ represents the connectivity of silicon tetrahedron attached to $m$ aluminate tetrahedra. From quantitative ${ }^{29} \mathrm{Si} \mathrm{NMR} \mathrm{spectra,} \mathrm{the}$ average length of $\mathrm{C}-\mathrm{S}-\mathrm{H}$ chains can be estimated from the relative intensities of the resonances as $2+$ $2 \times Q^{2} / Q^{1}$, as well as the advancement of the silicate hydration as $1-Q^{0}$. This last formula is quite easy to apply for hydrated CEM I where the $Q^{\circ}$ resonance is well defined but it is more complex for a cement paste with SCMs. Consequently, in this last case, the formula is adapted considering $Q^{\circ}$ as the sum of $Q^{o}$ from clinker $\left(C_{2} S\right.$ and $C_{3} S$ ) and also the anhydrous phase of SCM (GGBS and FA). However, there is no method to quantify unreacted $M K$ in a hydrating paste. Consequently, MK is considered full reacted in this study which is probably the case since hydrated cementitious materials are water cured during one year and the initial MK content is low. In these formulas, $Q^{n}$ represents the relative 
integrated intensities of the resonance assigned to that particular environment. The integrated intensities were obtained by fitting the spectra using the DMFIT freeware [30].

In this study, characterizations were made on the cement pastes, carbonated or not (TC and Ref samples). Due to the high number of samples, a selection of NMR experiments has been made and this study focuses on 6 different types of cement pastes: CEM I, CEM I MK(10\%), CEM I MK(25\%), CEM I FA(30\%), CEM III GGBS(62\%) and CEM III GGBS(82\%). The deconvolution parameters are put in appendix.

\subsection{Method used to quantify each phase of the cementitious matrix and complementary calculations}

The method used to quantify each phase from a combination of MAS NMR spectroscopy, elementary analysis by ICP-AES and TGA/DTA is fully described in [31] and will not be reproduced here. It will be denoted as "combined technique" in legend of the figures. For example, the molar stoichiometry of $\mathrm{C}-\mathrm{S}-\mathrm{H}$ (or C-A,S-H) is unknown in hydrated cement paste. Consequently, in order to calculate adequately the amount of $\mathrm{C}-\mathrm{S}-\mathrm{H}$ (or $\mathrm{C}-\mathrm{A}, \mathrm{S}-\mathrm{H})$, each constitutive oxide of this compound $\left(\% \mathrm{SiO}_{2}\right.$, $\% \mathrm{CaO}, \% \mathrm{Al}_{2} \mathrm{O}_{3}$ and $\% \mathrm{H}_{2} \mathrm{O}$ ) is distinctly quantified using various analytical and spectroscopic methods for $100 \mathrm{~g}$ of hydrated cement paste. $\% \mathrm{SiO}_{2}$ is obtained by ${ }^{29} \mathrm{Si} \mathrm{NMR,} \% \mathrm{Al}_{2} \mathrm{O}_{3}$ by ${ }^{27} \mathrm{Al} \mathrm{NMR,} \% \mathrm{H}_{2} \mathrm{O}$ by TGA. \% $\mathrm{CaO}$ is indirectly obtained considering the total amount of calcium minus the sum of all other phases containing calcium. Concerning measurement uncertainties, there are evaluated in studies based on TGA [32] but not in such studies based on NMR spectroscopy. However, they will be discussed in the results sections as well as the limits of the calculation methods used here.

In the particular case of the present study, these calculations notably take into account the dilution effect provided by $\mathrm{CO}_{2}$ incorporation (determined by TGA) in order to quantify adequately the elemental composition expressed in weight oxide $\left(\% \mathrm{SiO}_{2}, \% \mathrm{CaO}, \ldots\right)$ or weight phase (portlandite, ...) in the carbonated cement pastes.

The aim is not only to investigate the overall phase assemblage after carbonation and, in particular, the chemical transformations but also to have a detailed view on each phase.

\section{Results and discussion}

\section{1 Global comparison of phase assemblages before and after carbonation}

After the carbonation process (discussed in section 2.2), $\mathrm{CaCO}_{3}$ became as expected the major phase in terms of weight for all TC samples whatever the initial binder used (see figure 1) and these results are consistent with previous studies [6-9][33-39]. The mass proportion of $\mathrm{CaCO}_{3}$ in the totally carbonated OPC sample was over $60 \%$ for example. It is expected that this sample would contain more $\mathrm{CaCO}_{3}$, since it had the highest amount of calcium (the $\mathrm{CaO}$ amount of the clinker was $62 \%$ ). There was indeed a linear relationship between the amount of $\mathrm{CaCO}_{3}$ produced and the quantity of $\mathrm{CaO}$ in the anhydrous binders (see figure $2 \mathrm{~A}$ ) but this depended on the SCM type. The difference between MK and FA cement pastes on one hand and GGBS cement paste on the other hand was probably because calcium was present almost exclusively in the hydrated phases for the Ref samples with FA or MK while, for cement paste with GGBS, calcium was also in anhydrous phases (slag). According to the results reported in figure 1, there was still 15\% of unreacted GGBS in Ref CEM III GGBS(62\%) and $20 \%$ in Ref CEM III GGBS(82\%)). In addition, figure 2B showed the same data as those of figure $2 \mathrm{~A}$ but with $\mathrm{CaCO}_{3}$ amount reported to clinker. This $\mathrm{CaCO}_{3}$ amount was constant for TC CEM 
I, TC CEM I with MK or CEM I with FA (see figure 2B). This means that for these cement pastes, the $\mathrm{CaCO}_{3}$ amount formed by carbonation only depends on the initial amount of clinker contrarily to the case of cement paste with $\mathrm{GGBS}$. For them, $\mathrm{CaCO}_{3}$ amount increased with the initial amount of GGBS demonstrating that one depends on the other. The curve appeared less linear for these cement paste (see figure $2 \mathrm{~A}$ and $2 \mathrm{~B}$ ). However, the values obtained were calculated using the cement substitution level by GGBS. In this study however, commercial CEM III/A and CEM III/C were used and it is possible that the theoretical values of cement replacement by GGBS (62\% and $82 \%)$, were not exactly the same.

Obviously, hydrated and anhydrous phases did not exhibit the same reactivity to the carbonation process (see figure 3 in center). Consequently, the results presented in figure $2 B$ on sample carbonated after a long water curing time, should be not the same if the materials are carbonated at younger age. Indeed, at young age (before carbonation), the phase assemblage of a cement paste is quite different than at a longer age and specially according the type of cement paste $[31,40]$. For example, there are more anhydrous phases at a younger age and aluminate phases equilibrium is quite different in cement paste with SCM compared to CEM I cement paste. Nevertheless, carbonation of anhydrous phases $\left(\mathrm{C}_{2} \mathrm{~S}, \mathrm{C}_{3} \mathrm{~S}\right.$ and $\mathrm{GGBS}$ ) can also occur to a certain extent in aged materials. The hydration rate (obtained by ${ }^{29} \mathrm{Si} \mathrm{NMR} \mathrm{see} \mathrm{figure} 4$ ) increases after carbonation but no C-S-H is formed. $C_{3} S, C_{2} S$ and GGBS phases are therefore partially decalcified which is appeared by the $Q^{0}$ species forming directly $Q^{3}$ or $Q^{4}$ (silica gel) after carbonation and not $Q^{1}$ or $Q^{2}(C-S-H)$. In addition to a lower reactivity than for hydrated phases, accessibility of anhydrous phases $\left(\mathrm{C}_{3} \mathrm{~S}\right.$ and $\mathrm{C}_{2} \mathrm{~S}$ and GGBS) can be another explanation for not completed carbonation of these phases. In fact, hydrates form at the surface of anhydrous phases limiting carbonation process [41].

According to the results presented above, $\mathrm{CaCO}_{3}$ formed at the expense of portlandite and of other phases containing calcium. The manifestation of portlandite through its dehydration peak in DTG disappeared in all TC sample (see figure 5) but it must have persisted in small amount since small reflection peaks were still detectable on the diffractograms (except for CEM III GGBS(62\%) and CEM III GGBS(82\%)), see figure 6 . Therefore, the carbonation process had not completely consumed portlandite for these materials. In this case, the formation of calcium carbonate on the surface of portlandite crystals probably limited calcium dissolution from portlandite and it is also linked to carbonation process used, as previously reported [18],[41-43].

In conclusion, figure 1 shows a decrease of all phases (excepted $\mathrm{CaCO}_{3}$ ) for materials after carbonation. Nevertheless, there was a mass contribution by the $\mathrm{CO}_{2}$ entry that caused a dilution phenomenon in carbonated materials for all the $\mathrm{CO}_{2}$-free phases since $100 \mathrm{~g}$ of materials after $\mathrm{TC}$ is considered. Figure 3 (left) takes into account this dilution effect by relating the amounts of each hydrated phase to the initial amount of clinker. The results confirmed indeed that almost all phases decreased not only by dilution effect but also by degradation under carbonation and especially by the loss of calcium. Therefore, it is important to focus on the chemistry of calcium. 

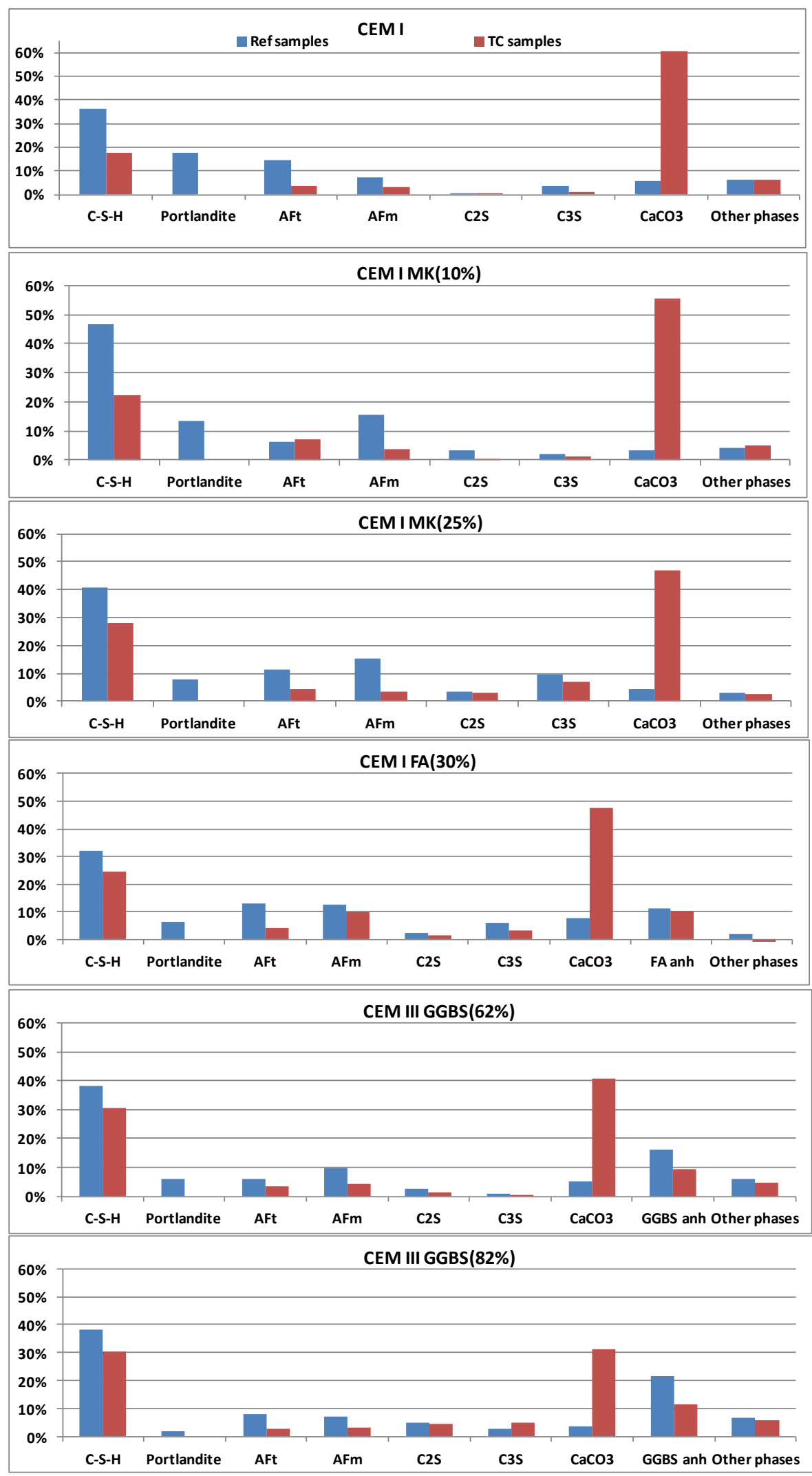

Figure 1: Comparisons of mass proportion between reference samples (Ref) and totally carbonated (TC) samples after 365-day water curing. Results are obtained by combined technique [31]. TC samples were carbonated until constant mass in chamber at $1.5 \% \mathrm{CO}_{2}$ and $65 \% \mathrm{RH}$, after 365 -day water curing. Here $\mathrm{C}-\mathrm{S}-\mathrm{H}=$ $\mathrm{C}-\mathrm{A}, \mathrm{S}-\mathrm{H}+$ silica gel and other=other phases $(\mathrm{TAH}, \mathrm{Iron}, \ldots$... AFt=Ettringite and AFm=Monocarboaluminate, Hemicarboaluminate, Monosulfoaluminate,... 


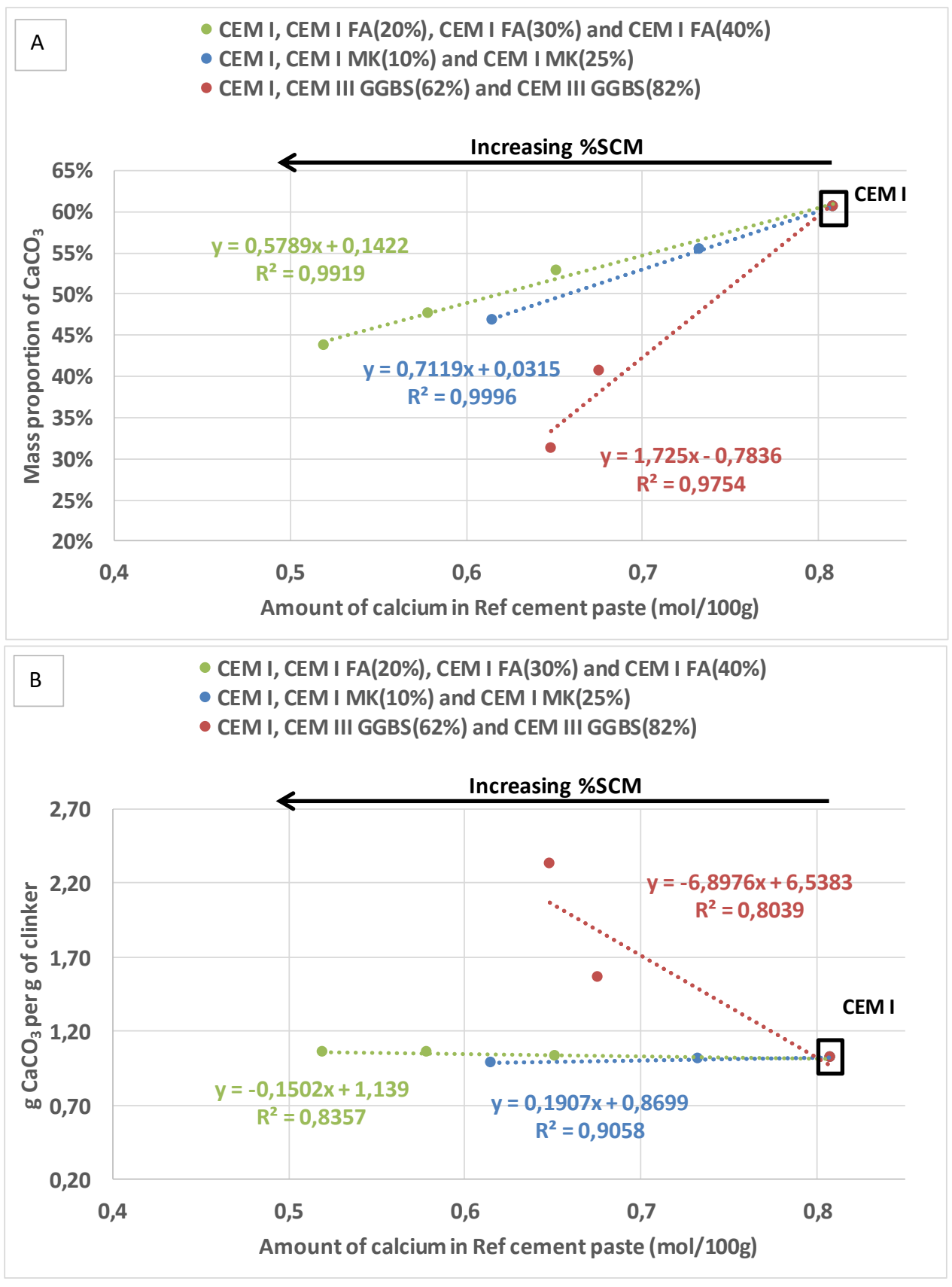

Figure 2: Comparison between the proportion of calcium in Ref cement paste assessed and the mass proportion of $\mathrm{CaCO}_{3}$ of the TC samples (A) or the mass proportion of $\mathrm{CaCO}_{3}$ reported to clinker (B), obtained by TGA. TC samples were carbonated until constant mass in chamber at $1.5 \% \mathrm{CO}_{2}$ and $65 \% \mathrm{RH}$, after 365 -day water curing. 


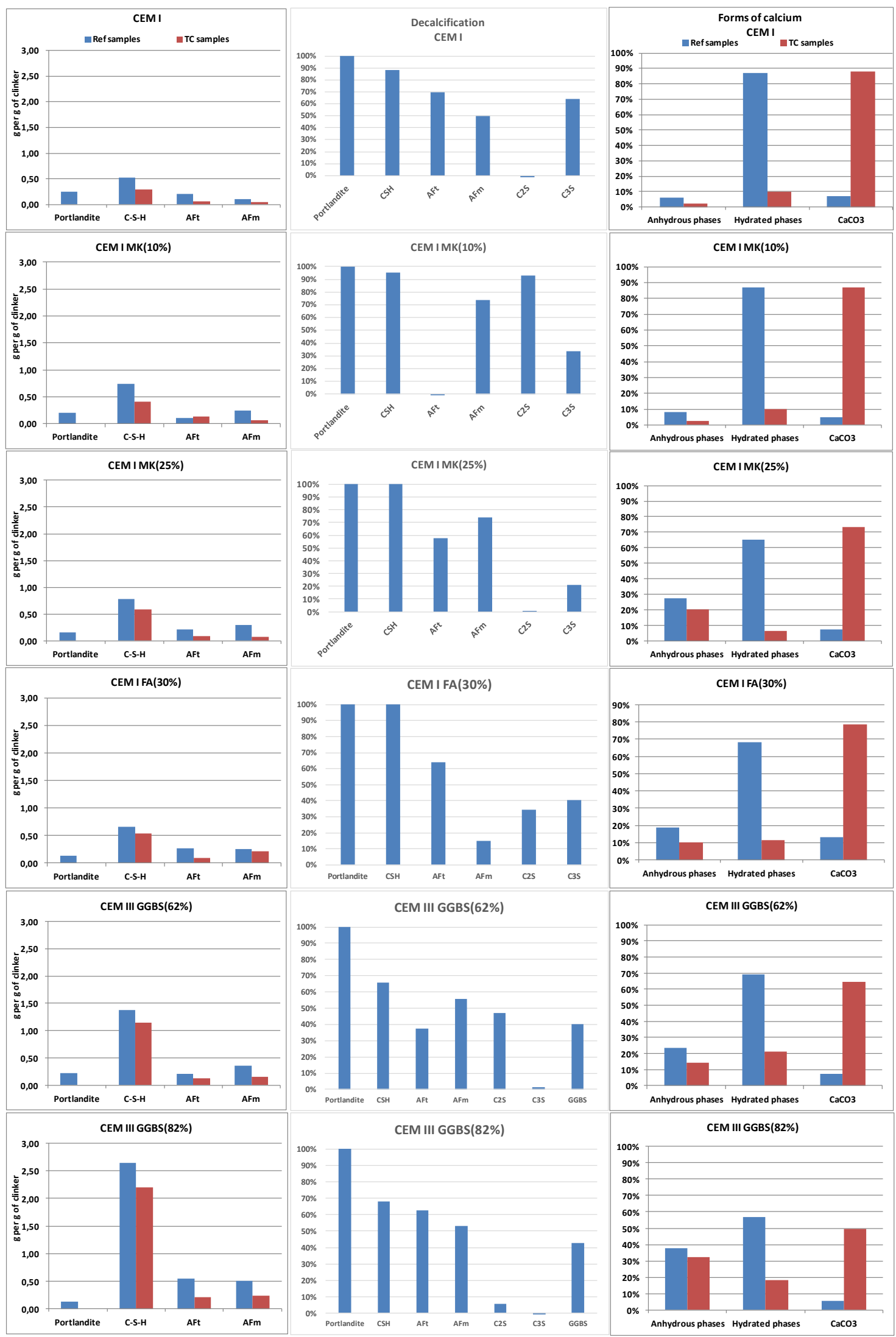

Figure 3: Mass proportion reported to clinker (in left), decalcification of each phase (in middle) and forms of calcium in cement pastes (in right) after 365-day water curing. Results are obtained by combined technique. Decalcification corresponds to calcium loss for each phase between TC and Ref sample. TC samples were carbonated until constant mass in chamber at $1.5 \% \mathrm{CO}_{2}$ and $65 \% \mathrm{RH}$, after 365 -day water curing. $\mathrm{Here} \mathrm{C}-\mathrm{S}-\mathrm{H}=$ 
$\mathrm{C}-\mathrm{A}, \mathrm{S}-\mathrm{H}+$ silica gel, AFt=Ettringite and AFm=Monocarboaluminate, Hemicarboaluminate, Monosulfoaluminate,....
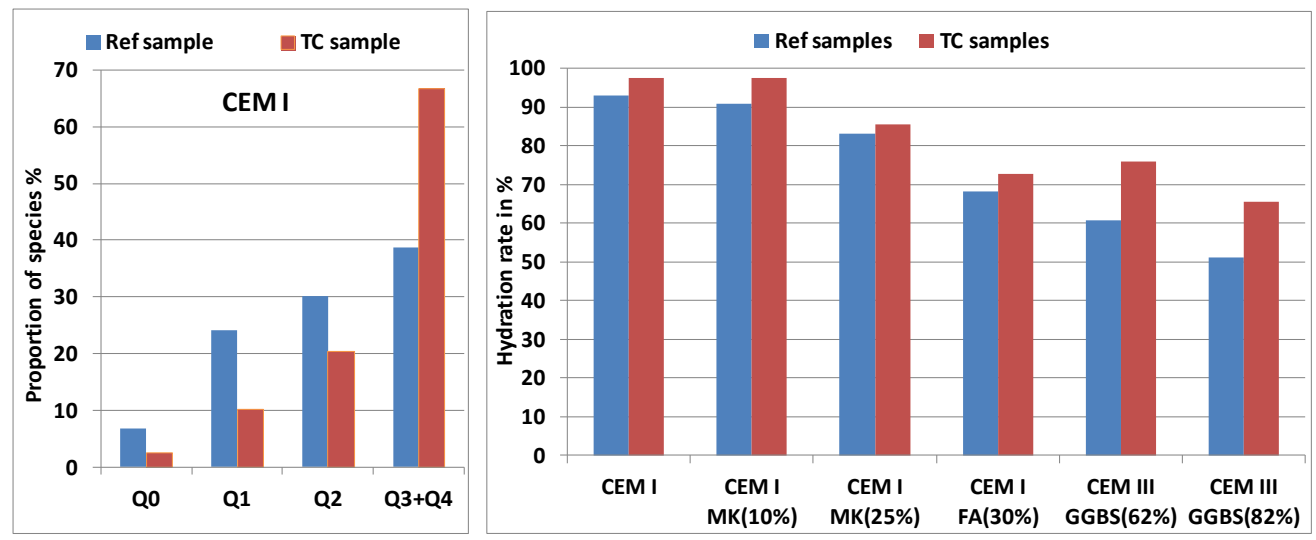

Figure 4: Deconvolution example of ${ }^{29} \mathrm{Si}$ NMR spectra and hydration rate obtained ${ }^{29} \mathrm{Si}$ by NMR for reference (Ref) samples and totally carbonated (TC) ones (carbonation until constant mass in chamber at $1.5 \% \mathrm{CO}_{2}$ and $65 \% \mathrm{RH}$ ) after 365-day water curing. 

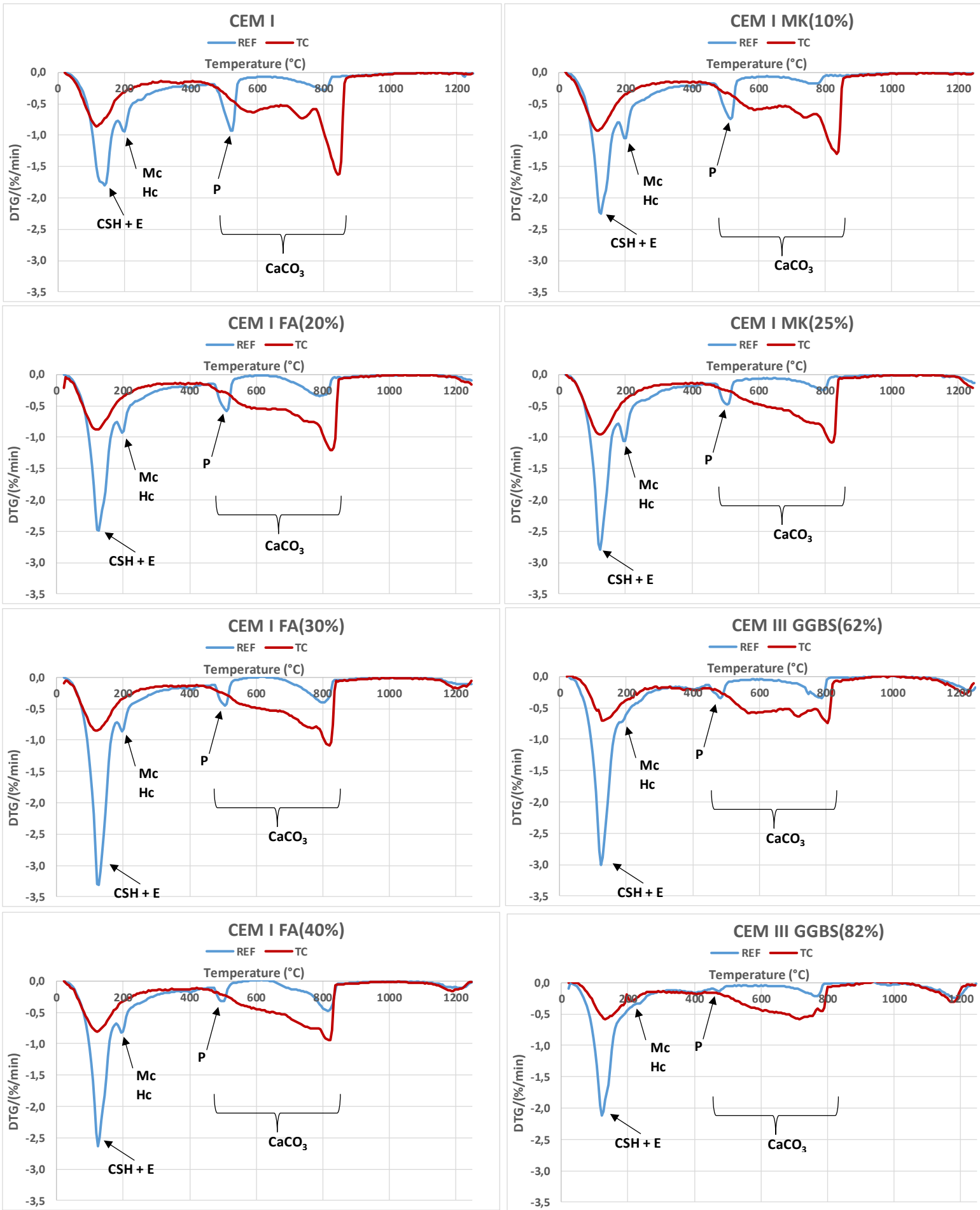

Figure 5: DTG patterns of cement pastes for Ref and TC samples. TC samples were carbonated until constant mass in chamber at $1.5 \% \mathrm{CO}_{2}$ and $65 \% \mathrm{RH}$ after 365 -day water curing. Ettringite (E), Portlandite (P), monocarboaluminate $(\mathrm{Mc})$ and hemicarboaluminates $(\mathrm{Hc})$. 

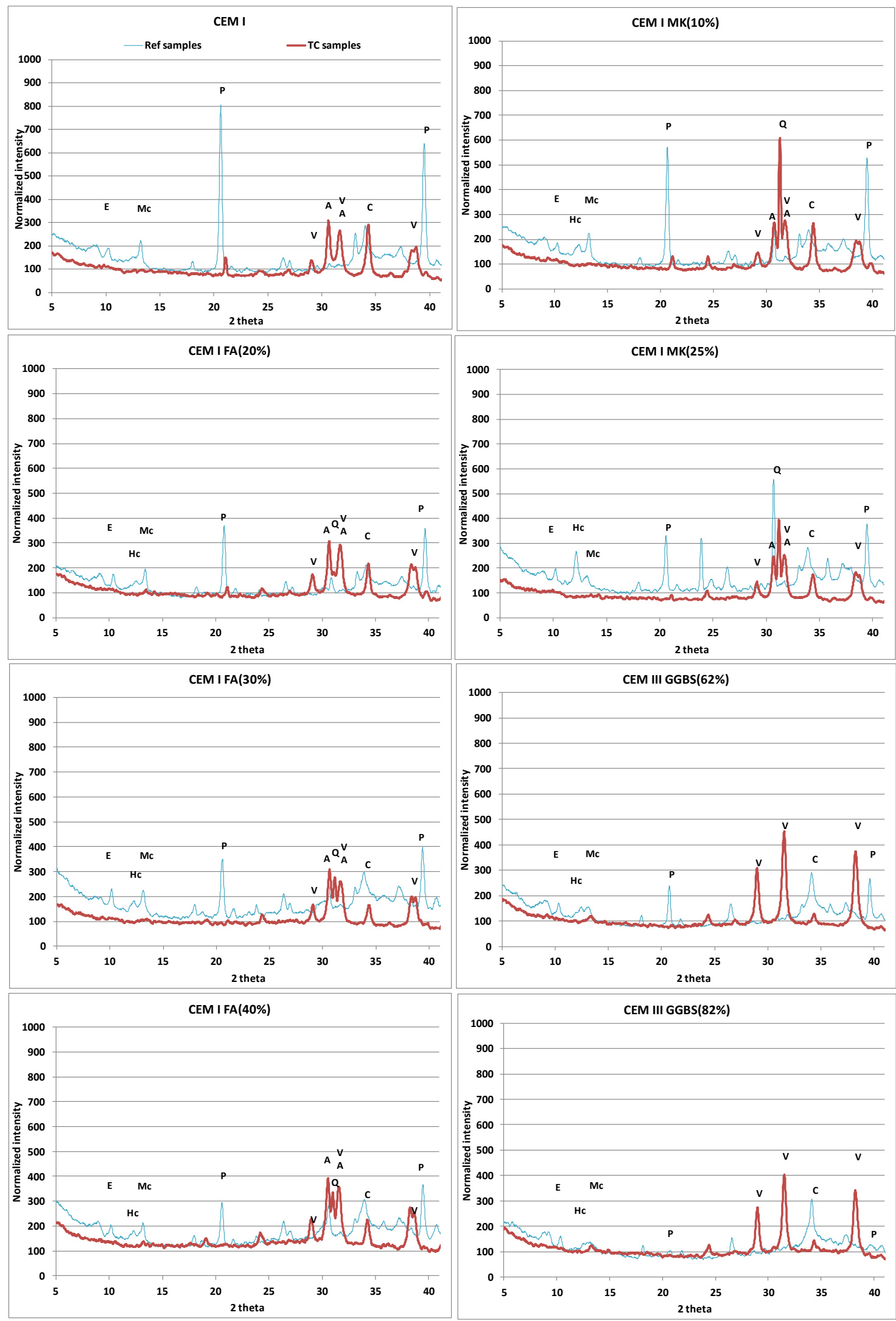

Figure 6: Partial XRD patterns of cement pastes for Ref and TC samples (normalized intensity in counts). TC samples were carbonated until constant mass in chamber at $1.5 \% \mathrm{CO}_{2}$ and $65 \% \mathrm{RH}$ after 365 -day water curing. Ettringite $(E)$, Portlandite $(P)$, calcite $(C)$, vaterite $(V)$, aragonite $(A)$, quartz $(Q)$, monocarboaluminate $(M c)$ and hemicarboaluminates $(\mathrm{Hc})$. 


\subsection{Chemistry of calcium before and after carbonation}

From figure 1 and with all combined techniques, it was possible to calculate the evolution of each phase containing calcium as a function of $\mathrm{CO}_{2}$ bound (see figure 7 ) showing the partial transformation of each phase in calcium carbonate. This representation is particularly interesting since it presents thermodynamic equilibrium of the phases containing calcium before and after carbonation.

In addition, TGA technique directly provided the total amount of $\mathrm{CaCO}_{3}$ produced (see orange lines in figure 8). This amount can also be calculated by accounting the calcium loss for each of the sample phases that have been degraded between the Ref and TC sample (taking account the dilution effect as for figure 3 in middle) obtained from all combined techniques. When comparing both results on the same figure (Figure 8), they were very close for TC samples of CEM I, CEM I MK(10\%), CEM III GGBS(62\%) and CEM III GGBS(82\%). For the other TC samples (CEM I MK(25\%) and CEM I FA(30\%), the overall amount obtained directly by TGA (orange line) was higher than the one calculated for each degraded phase obtained by all combined techniques. This underestimation of the decalcification of the cementitious phases was probably due to the fact that some phases which contain calcium ( $\mathrm{TAH}, \mathrm{C}_{3} \mathrm{~A}$, ferrite phases ...) were not taken into account in the calculations. An additional explanation might be that some of these phases may have been only partially decalcified and have remained their structure and therefore still appeared in NMR spectroscopy in the form of AFt (Ettringite) and AFm phases. In fact, the problem is that calcium is not directly observed by any method used here, contrary to silica (by ${ }^{29} \mathrm{Si} N \mathrm{NR}$ ) or alumina (by ${ }^{27} \mathrm{Al} \mathrm{NMR}$ ) and when a compound is observed (for example ettringite by ${ }^{27} \mathrm{Al} N \mathrm{NMR}$ ), its molar formulae had to be supposed constant which might possibly not be completely true after carbonation.

Concerning the produced $\mathrm{CaCO}_{3}$, in XRD pattern of carbonated samples (see figure 6), vaterite (peak

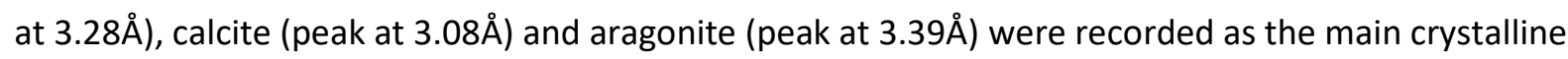
phases as already observed by previous studies $[4,6,9]$. DTG results showed also that $\mathrm{CaCO}_{3}$ was present in various forms (see figure 5). The polymorphism of $\mathrm{CaCO}_{3}$ crystal depends on the cementitious phase from which it was formed, the $\mathrm{pH}$ of the pore solution and on the temperature $[43,44]$. Portlandite generally induces the formation of calcite while the other phases (C-S-H and aluminates phases) tend to form vaterite and aragonite which both evolve to calcite with time [44]. The present study is in agreement with the literature. In fact, the Rietveld analysis applied to the TC CEM I paste shows that there are $38 \%$ of crystalized $\mathrm{CaCO}_{3}$ in the form of vaterite, $41 \%$ as aragonite and $21 \%$ as calcite, while the proportions for the CEM III GGBS(82\%) sample are $94 \%$ as vaterite, $1 \%$ as aragonite and $5 \%$ as calcite. According to figure 8 , calcium present in $\mathrm{CaCO}_{3}$ comes mainly from C$\mathrm{S}-\mathrm{H}$ for CEM III GGBS (only $2 \%$ of portlandite in ref CEM III GGBS(82\%) vs $18 \%$ in ref CEM I), while the source of calcium is shared between C-S-H and portlandite in the case of the CEM I sample. It confirms that vaterite was formed from the C-S-H and that its presence is an indicator of the degradation (decalcification) of the C-S-H. However, the aragonite amount was high in TC sample (except CEM III with GGBS) and this cannot be explained solely in this way. Indeed, it is known that the carbonation conditions and drying pretreatment $\left(\mathrm{RH}, \mathrm{T}\right.$, level of $\mathrm{CO}_{2}$, the duration,...) of cement paste can also influence this $\mathrm{CaCO}_{3}$ phase assemblage [44-46]. Finally, DTG results (see figure 5) seemed to indicate there was amount of amorphous $\mathrm{CaCO}_{3}$ (in addition to crystalized forms) which could not be quantified by XRD, consequently it was not possible to quantify precisely each phase of $\mathrm{CaCO}_{3}$ and the values of Rietveld analysis given below are at best semi-quantitative. 
In conclusion, all phases containing calcium participate at the formation of $\mathrm{CaCO}_{3}$ as for example hydrated aluminate phases. Therefore, it is also interesting to focus on equilibrium of aluminate phases before and after carbonation.

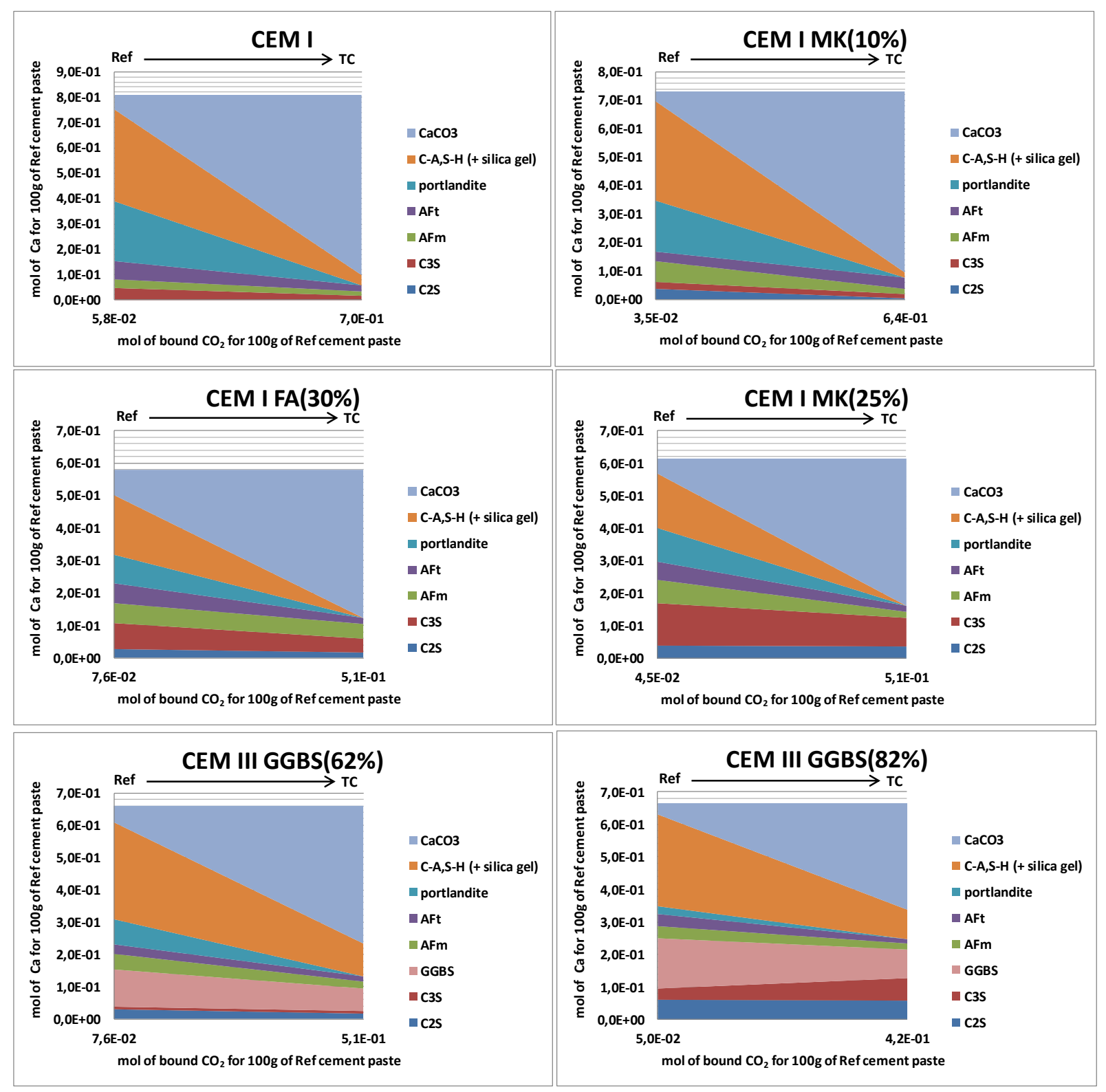

Figure 7: Evolution of the phase assemblage containing calcium as a function of $\mathrm{CO}_{2}$ bound by cement paste obtained by combined technique. This figure takes account the dilution effect. TC samples were carbonated until constant mass in chamber at $1.5 \% \mathrm{CO}_{2}$ and $65 \% \mathrm{RH}$, after 365-day water curing. Here, $\mathrm{AFt}=\mathrm{Ettringite}$ and AFm=Monocarboaluminate, Hemicarboaluminate, Monosulfoaluminate,.... For CEM III GGBS(82\%), the increase of $\mathrm{C}_{3} \mathrm{~S}$ is considered to be due to the uncertainties. 


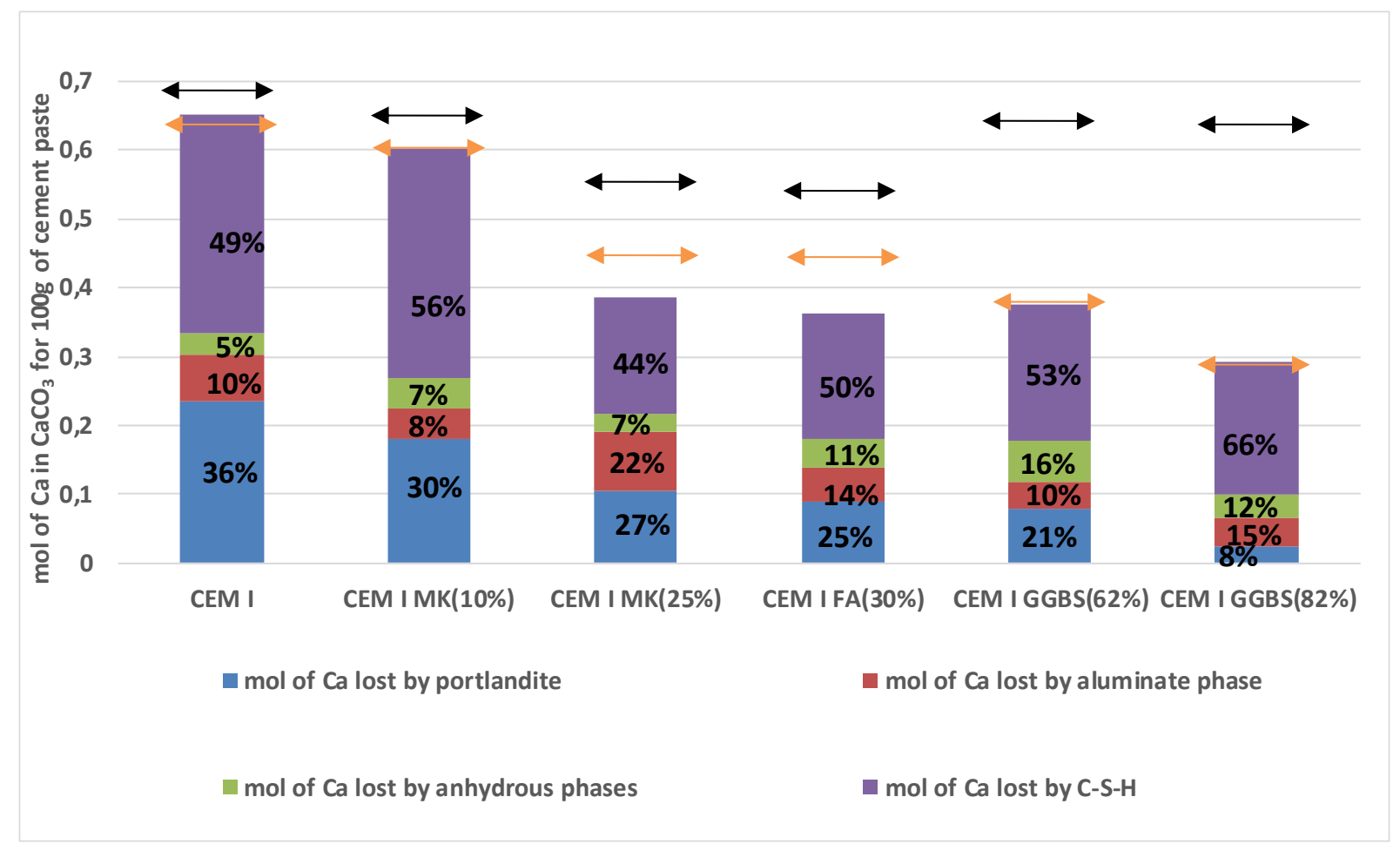

Figure 8: Molar amount of calcium in $\mathrm{CaCO}_{3}$ produced as a function of each phases for $100 \mathrm{~g}$ of TC samples assessed by combined technique compared to the total amount of $\mathrm{CaCO}_{3}$ produced during carbonation directly assessed by TGA (orange line) and the total amount of calcium in TC samples assessed by elementary analysis and TGA (black line). The difference between orange line and black line correspond to the amount of non carbonated calcium. TC samples were carbonated until constant mass in chamber at $1.5 \% \mathrm{CO}_{2}$ and $65 \% \mathrm{RH}$, after 365-day water curing. Here $\mathrm{C}-\mathrm{S}-\mathrm{H}=\mathrm{C}-\mathrm{A}, \mathrm{S}-\mathrm{H}+$ silica gel, aluminate phase $=\mathrm{AFm}+\mathrm{AFt}$. AFt=Ettringite and AFm=Monocarboaluminate, Hemicarboaluminate, Monosulfoaluminate,...

\subsection{Chemistry of alumina phases}

The significant presence of vaterite and aragonite showed that there was degradation of the C-S-H and probably of the aluminate phases, since the amounts of ettringite and AFm decreased according to ${ }^{27} \mathrm{Al}$ NMR results (see figure 9). Ettringite and AFm phases in TC cement pastes with SCM decreased at the benefit of $\mathrm{AI}(\mathrm{IV})$ and AI(V). For example, the CEM III GGBS(82\%) TC sample has $80 \%$ of its aluminum in tetrahedral/ pentahedral coordination when it was $42 \%$ in the Ref sample. The effect of carbonation on aluminate phases is not fully documented. According to previous studies [4][35-36][47-50], the aluminate phases AFm and ettringite, under carbonation, decompose to form gypsum, calcium carbonate and alumina gel. About the latter, some authors demonstrated gibbsite formation for carbonation of high aluminate cement pastes [51-55]. In the present study, the formation of gypsum (or even anhydrite) was not observed by XRD (see figure 6) while the increase in $\mathrm{Al}(\mathrm{IV})$ cannot be explained by the formation of alumina gel where aluminum is hexacoordinated. XRD did not reveal gibbsite for TC CEM I FA(30\%), CEM I FA(40\%), CEM III GGBS(62\%) and CEM III GGBS(82\%), as shown by other authors for carbonated cement materials close to ours, (e.g. [46][5657]). For other TC cement pastes, gibbsite presence is uncertain since its main peak is too close to the one of remaining portlandite and the same observation can be made for the other polymorphic forms (nordstrandite or bayerite). Finally, TGA/DTG showed no peak indicating the presence of gibbsite, nordstrandite or bayerite (according theoretical positions mentioned by [54]).

Consequently, degradation products of hydrated aluminous phases seemed to be mainly amorphous. 
In addition, the amount of TAH seemed to increase for TC samples (except for CEM III GGBS(62\%) and CEM III GGBS(82\%)). According [26,26], TAH is an amorphous/disordered aluminum hydroxide or a calcium aluminate hydrate. In the first hypothesis, for the present study, it would be expected that after carbonation, TAH would increase since the amount of AFm and AFt phases decreased and they would probably form this amorphous/disordered aluminium hydroxide in process similar to the transformation of C-S-H into a silica gel with a small part of calcium $[9,18]$. In the opposite case, the amount of TAH decreased for TC CEM III GGBS(62\%) and CEM III GGBS(82\%). As this phase is degraded (see figure 9), TAH should contain calcium before carbonation. Consequently, TAH would be more a calcium aluminate hydrate (second hypothesis) since it corresponds to a decalcification to this compound during carbonation. It remains nevertheless possible that the TAH NMR resonance does not correspond always to the same compound depending on the initial binder (type of SCM). Consequently, TAH would be an amorphous/disordered aluminum hydroxide for Ref cement pastes CEM I, CEM I with MK or FA and TAH would be a calcium aluminate hydrate for Ref cement pastes CEM III GGBS(62\%) and CEM III GGBS(82\%). However, the real composition of TAH is probably more complex.

In addition to the degradation of Ettringite and AFm phases, equilibrium of hydrated calcium aluminate phase was also modified (see AFm/AFt ratio in figure 10 with AFt=Ettringite) as also noticed by [58]. The tendency between Ref and TC samples was not clear. It seems that the more the $\mathrm{AFm} /$ ettringite ratio is high for reference samples, the more the decrease of this ratio is important for carbonated materials. It is probably due to $\mathrm{SO}_{3}$ releasing in porous solution during carbonation (=degradation) of aluminate phases, making ettringite more stable in these conditions. Regardless, the overall decrease of the sulfoaluminate phases after carbonation meant obviously that some of the chemically bound $\mathrm{SO}_{3}$ initially present in theses phases was released. Consequently, the questions are where is it (physically bound by C-S-H or as free sulphates in porous solution) and are there consequences on durability (e.g. concerning possible formation of expansive compound with sulphate)? Unfortunately, the technics used in the present study cannot answer to these questions. Moreover, concerning AFm/ettringite equilibrium, ettringite formation needs 6 calcium atoms per aluminate against 3 calciums for AFm phase formation and most of the calcium tends to precipitate in $\mathrm{CaCO}_{3}$ in the pore solution. Consequently, it is not obvious to understand why ettringite would be more stable than AFm phases in these conditions. Moreover, it is well known that AFm phases can react with carbonates $\left(\mathrm{CO}_{3}{ }^{2-}\right)$ to form monocarboaluminates [4],[36-39]. However, in the present study, XRD showed no ettringite or monocarboaluminate in TC samples in comparison to Ref samples (figure 6). On the contrary, even when these compounds (monocarboaluminate or hemicarboaluminate or ettringite) were there in reference cement pastes (before carbonation), they disappeared after carbonation confirmed also by DTG results (see figure 5).

In conclusion, most of hydrated aluminate phases were degraded during carbonation. However, even if a part of these compounds (Ettringite, Monocarboaluminate, ....) is still present as shown by ${ }^{27} \mathrm{Al}$ NMR, they are probably very amorphous/disordered phases. After degradation of hydrated aluminate phase, a part of aluminate seems to go in C-S-H since it appears by ${ }^{27} \mathrm{Al} \mathrm{NMR}$ that AI(IV) and $\mathrm{Al}(\mathrm{V})$ amount increases after carbonation, therefore $\mathrm{C}-\mathrm{S}-\mathrm{H}$ is studied in details in the following section as well as its degradation product (silica gel). 


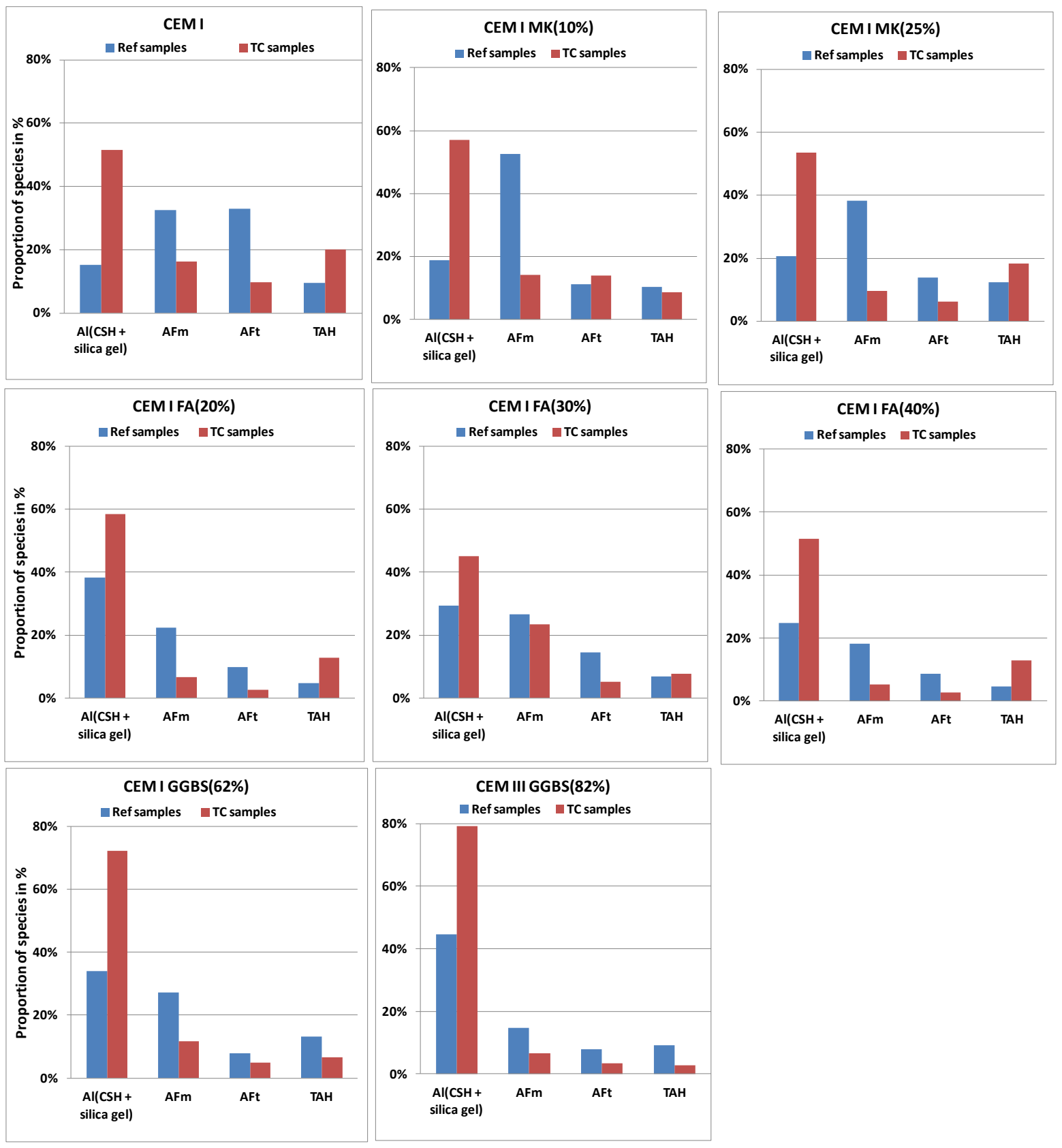

Figure 9: Proportion of Al species in cement pastes before and after total carbonation (carbonation until constant mass in chamber at $1.5 \% \mathrm{CO}_{2}$ and $65 \% \mathrm{RH}$, after 365 -day water curing), obtained by ${ }^{27} \mathrm{Al} \mathrm{NMR}$. Here, $\mathrm{AFt}=\mathrm{Ettringite}$ and $\mathrm{AFm}=$ Monocarboaluminate, Hemicarboaluminate, Monosulfoaluminate,.... 


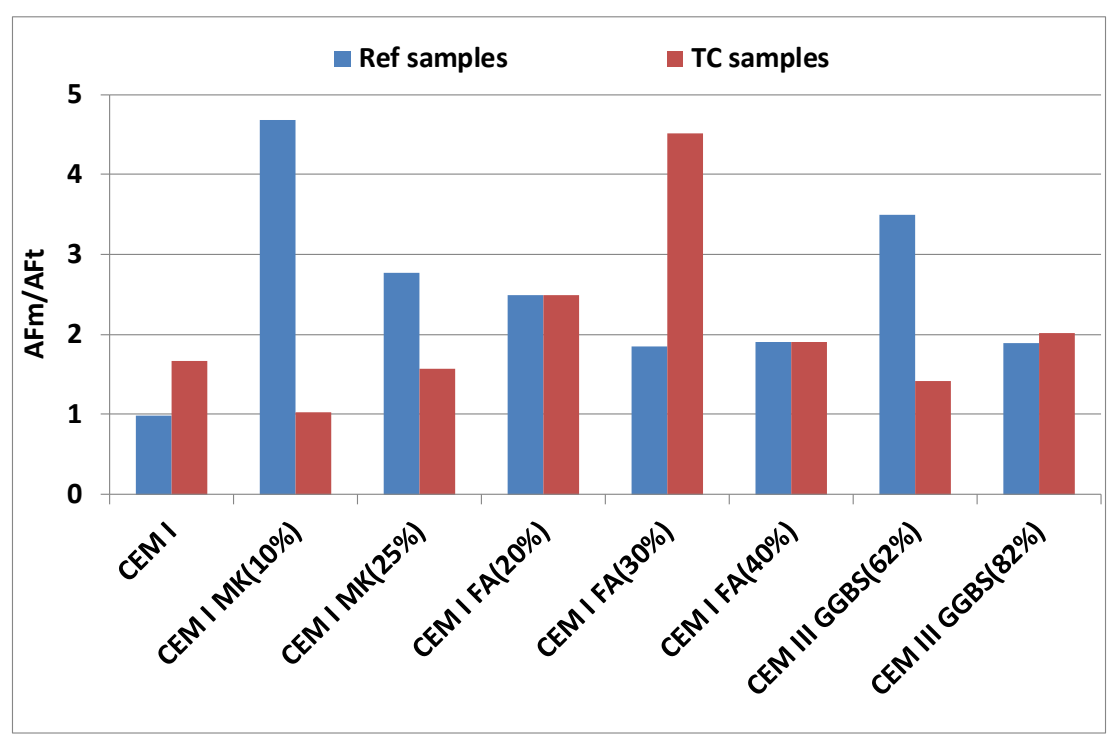

Figure 10: AFm/AFt ratio of reference (Ref) samples and totally carbonated (TC) ones (carbonation until constant mass in chamber at $1.5 \% \mathrm{CO}_{2}$ and $65 \% \mathrm{RH}$ ) after 365 -day water curing, obtained by ${ }^{27} \mathrm{Al}$ NMR. Here, $\mathrm{AFt}=\mathrm{Ettringite}$ and $\mathrm{AFm}=$ Monocarboaluminate, Hemicarboaluminate, Monosulfoaluminate,.... The value for TC CEM I (30\%) is very high and believe to be an aberrant value.

\subsection{Modifications of C-A,S-H after carbonation}

After carbonation C-S-H (or C-A,S-H) is considered to become a silica gel with a small part of calcium $[8,9,20,59]$. In general, C-S-H (or C-A,S-H) of reference cement pastes is characterized by different values: mean chain length $(\mathrm{MCL})$, ratio of $\mathrm{C} / \mathrm{S}$, ratio of $\mathrm{H} / \mathrm{S}$ and alumina content. The following part will discuss the effects of carbonation on all these points.

As expected, the $\mathrm{C} / \mathrm{S}$ ratio of the $\mathrm{C}-\mathrm{S}-\mathrm{H}$ decreased in all TC samples (see figure 11) confirming thereby the massive decalcification of the C-S-H. For example (see figures 3 and 7), over $65 \%$ of calcium moved for CEM III GGBS(82\%) and 100\% for CEM I MK(25\%) and CEM I FA(30\%). The average lengths of the C-S-H chains increased for all TC samples (see figure 11). Furthermore, the degradation products $\mathrm{C}-\mathrm{S}-\mathrm{H}\left(\mathrm{Q}^{3}+\mathrm{Q}^{4}\right)$ also increased at the expense of the amount of $\mathrm{C}-\mathrm{S}-\mathrm{H}\left(\mathrm{Q}^{1}+\mathrm{Q}^{2}\right)$ (see example in figure 4). The C-S-H chains polymerized to form a substantial silica gel.

The proportion of alumina in the C-S-H phases (or more likely C-A,S-H+silica gel) increased for TC samples (see figure 11 and also figure 9). The alumina content in the C-S-H was between 9 and 23\% for TC samples depending of the binder and in particular of the initial alumina content (linear tendency is observed). Such an increase in the alumina content (comparing before and after carbonation samples) results from two phenomena. First, there is actually an incorporation of aluminum from the degraded AFt and AFm phases during carbonation. The second effect is a departure of calcium and water from degraded C-S-H during carbonation and this induces a decrease in the C-S-H amount in all the TC samples. The relative proportion of aluminum (initially present) therefore increases. Nevertheless, in this study, C-S-H with aluminate phases formed an aluminosilicate gel during carbonation rather than just silica gel. In addition, the deconvolution of the ${ }^{29} \mathrm{Si} N \mathrm{NR}$ spectra of carbonated samples also showed the possible presence of $\mathrm{Q}^{4}(1 \mathrm{Al})$ or even $Q^{3}(1 \mathrm{Al})$, in addition to the $Q^{4}$ and $Q^{3}$ species. $Q^{4}(1 \mathrm{Al})$ represents silicon surrounded by four neighbors where one is aluminum, confirming thereby the ${ }^{27} \mathrm{Al} N \mathrm{NMR}$ results. This result seems to be confirmed by recent studies on carbonated synthetic C-A,S-H samples [60]. 
The amounts of C-A,S-H and silica gel are grouped in Figure 1, (called "C-S-H") since it is quite difficult to clearly separate them. However, in this study, two methods were proposed and compared in order to separate the silica gel from the C-S-H. In fact, by ${ }^{29} \mathrm{Si} N M R, \mathrm{Q}^{1}$ and $\mathrm{Q}^{2}$ represent only the C-S$H$ and $Q^{3}$ and $Q^{4}$ represent only the silica gel obtained after carbonation (decalcification) of the C-S-H. These two different proportions can thus be obtained directly in the present study (see Table 3), according the following equation:

$$
C-S-H \stackrel{\mathrm{CO}_{2}}{\longrightarrow} \mathrm{C}-\mathrm{S}-\mathrm{H}\left(\text { with } Q^{1} \text { and } Q^{2}\right)+\mathrm{SiO}_{2} \cdot \mathrm{mH}_{2} \mathrm{O}\left(\text { with } Q^{3} \text { and } Q^{4}\right)
$$

With $Q^{1}, Q^{2}, Q^{3}$ and $Q^{4}$ determined by ${ }^{29} \mathrm{Si}$ NMR

These results can be compared with another method. Indeed, with the results of this study, the molar amounts of $\mathrm{SiO}_{2}, \mathrm{CaO}, \mathrm{H}_{2} \mathrm{O}, \mathrm{Al}_{2} \mathrm{O}_{3}$ (of what is called $\mathrm{C}-\mathrm{S}-\mathrm{H}+$ silica gel) are obtained by combined technique, before and after carbonation. It is therefore also possible to obtain each of these 2 different proportions ( $\mathrm{C}-\mathrm{S}-\mathrm{H}$ and silica gel) assuming that the $\mathrm{C}-\mathrm{S}-\mathrm{H}$ have at least a $\mathrm{C} / \mathrm{S}=0.6$ before and after carbonation, according the following equation:

$$
C-S-H \stackrel{\mathrm{CO}_{2}}{\longrightarrow} \mathrm{C}-\mathrm{S}-\mathrm{H}(\text { with } \mathrm{C} / \mathrm{S}=0.6)+\mathrm{SiO}_{2} \cdot \mathrm{mH}_{2} \mathrm{O}
$$

With $\mathrm{SiO}_{2} \cdot \mathrm{mH}_{2} \mathrm{O}$ equal to $(\mathrm{C}-\mathrm{S}-\mathrm{H}+$ silica gel $)-\mathrm{C}-\mathrm{S}-\mathrm{H}($ with $\mathrm{C} / \mathrm{S}=0.6)$

For example, these calculations give $11 \%$ of silica gel and $7 \%$ of C-S-H (see table 3 ) in the carbonated CEM I paste. It is thus possible to compare the Si molar ratios of silica gel on C-S-H between the two methods. For the CEM I sample, the molar ratio silica gel on C-S-H is relatively close for both methods. On the other hand, for all the other TC samples, this ratio is very different according to the method used. For example, for CEM I MK (25\%), according to the analyzes, there would be no calcium in what appears then as only a silica gel. However, the NMR shows species $Q^{1}$ and $Q^{2}$, thus there is still "C-S-H type" structure in this sample. Maybe some of the decalcified C-S-H would retain their structure locally without calcium or more probably the aluminum would replace the calcium in the structure and would not modify it. However, if alumina takes place of calcium $\left(\mathrm{Ca}^{2+}\right.$ by $\left.\mathrm{Al}^{3+}\right)$, there are consequences on charge equilibrium and the surface charge and also on durability (e.g. physical chloride binding after carbonation [34]). Finally, C-S-H crystalline presence seems to disappear (no hump in the area of $30-40^{\circ}$ in 2 theta patterns, see figure 6 ).

In conclusion, the product of C-S-H degradation is poor in calcium (containing none for cement paste with $\mathrm{FA}$ and $\mathrm{MK}$ ), very amorphous/disordered and incorporate probably aluminate. In addition, the $\mathrm{H} / \mathrm{S}$ ratio of the $\mathrm{C}-\mathrm{S}-\mathrm{H}$ decreases for TC samples (see figure 11 ). When polymerizing, the $\mathrm{C}-\mathrm{S}-\mathrm{H}$ chains release water and this water is probably evaporated during the time in carbonation chamber ( $\mathrm{RH}$ $65 \%$ and $\mathrm{T}=20^{\circ} \mathrm{C}$ ). Consequently, there is probably a coupling effect between carbonation and drying as reported $[39,40]$ and it will be discussed in the following section. 
Table 3: Comparison of C-S-H and silica gel amount in TC samples. TC samples were carbonated until constant mass in chamber at $1.5 \% \mathrm{CO}_{2}$ and $65 \% \mathrm{RH}$ after 365-day water curing. For the 4 columns (in left), it is assumed that $\mathrm{C}-\mathrm{S}-\mathrm{H}$ have $\mathrm{C} / \mathrm{S}=0.6$ and same $\mathrm{H} / \mathrm{S}$ than ref samples, obtained by combined technique. For the column (in right), the ratio is obtained directly by ${ }^{29} \mathrm{Si} \mathrm{NMR}$.

\begin{tabular}{|l|l|l|l|l||l|}
\hline & $\begin{array}{l}\text { C-S-H + silica } \\
\text { gel } \\
(\% \mathrm{~m})\end{array}$ & $\begin{array}{l}\text { C-S-H } \\
(\% \mathrm{~m})\end{array}$ & $\begin{array}{l}\text { Silica gel }(\% \mathrm{~m}) \text { and } \\
(\mathrm{H} / \mathrm{S})\end{array}$ & $\begin{array}{l}\text { Molar ratio } \\
\text { Sisilica gel } \\
\text { Sic-s-H }\end{array}$ & $\begin{array}{l}\text { Molar ratio } \\
\text { Sisilica ge/ Sic-s-H directly } \\
\text { obtained by NMR }\end{array}$ \\
\hline CEM I & 18 & 7 & $11(0.8)$ & 2.1 & 2.2 \\
\hline CEM I MK(25\%) & 28 & 0 & $28(1.3)$ & $\mathrm{X}$ & 2.2 \\
\hline CEM I FA(30\%) & 25 & 0 & $25(1.9)$ & $\mathrm{X}$ & 1.9 \\
\hline $\begin{array}{l}\text { CEM III } \\
\text { GGBS(62\%) }\end{array}$ & 30 & 24 & $6(1.0)$ & 0,4 & 22 \\
\hline $\begin{array}{l}\text { CEM III } \\
\text { GGBS(82\%) }\end{array}$ & 30 & 23 & $7(0.2)$ & 0.6 & 10 \\
\hline
\end{tabular}
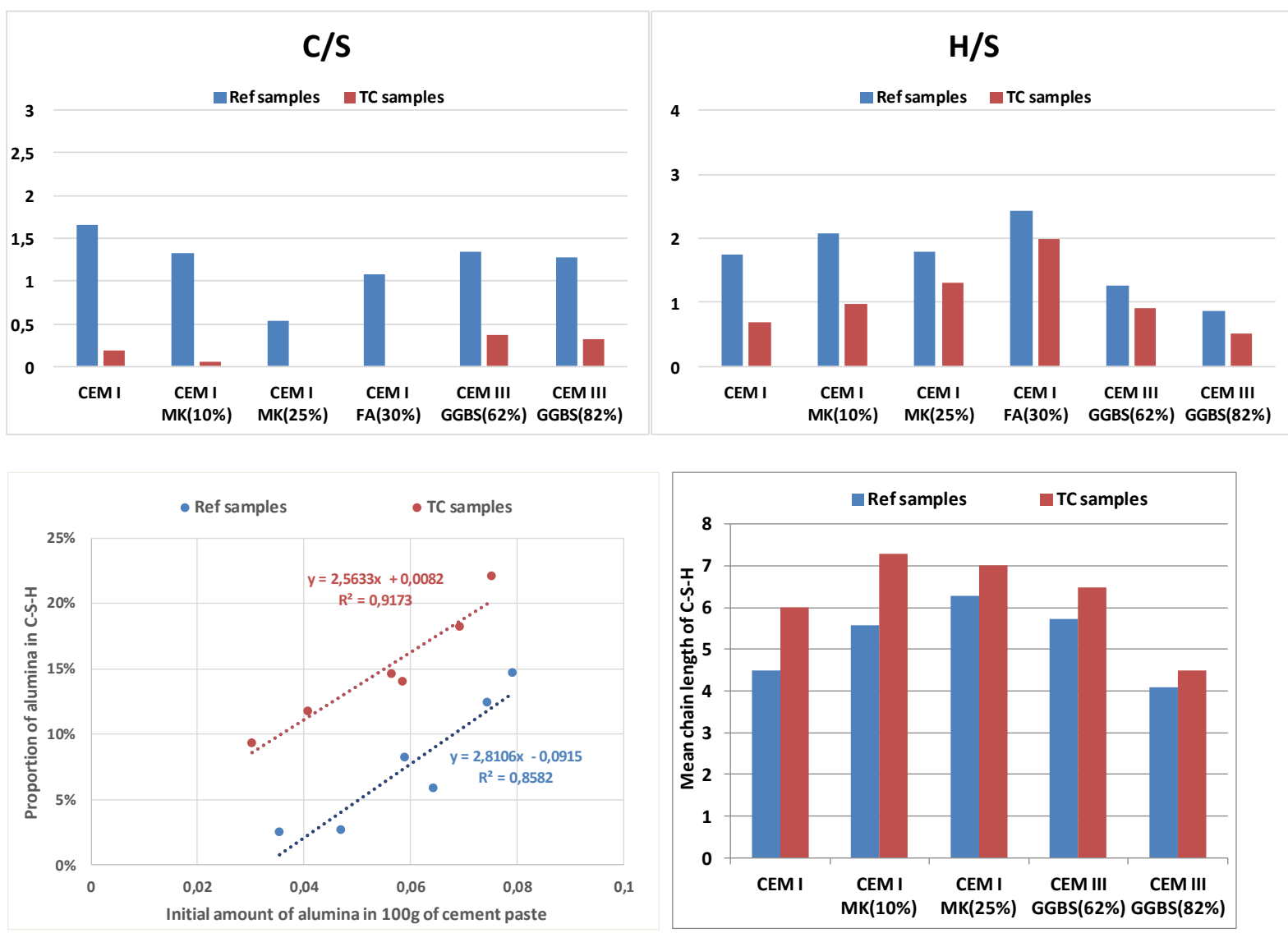

Figure 11: C/S ratio, $\mathrm{H} / \mathrm{S}$ ratio, molar proportion of alumina, obtained by combined technique and Mean chain length in C-S-H (+silica gel) of reference (Ref) samples and totally carbonated (TC) ones (carbonation until constant mass in chamber at $1.5 \% \mathrm{CO}_{2}$ and $65 \% \mathrm{RH}$ ) after 365 -day water curing, obtained by ${ }^{29}$ Si NMR.

\subsection{Information obtained on water loss due to coupling effect of drying and carbonation}

From TGA/DTG results (see figure 5), it is possible to obtain the total amount of water loss between Ref and TC samples (see figure 12 ) in the range of $20-550^{\circ} \mathrm{C}$. These results take into account the dilution effect (reported to cement amount) and the water contained in porosity determined by 
drying at $40^{\circ} \mathrm{C}$ until constant mass was retrieved. During carbonation, samples lost more than $40 \%$ of their water and there is obviously no SCM effect on these water losses. Consequently, the water released during carbonation process of hydrated phases, did not stay in the porosity but it was evaporated due to dry condition in carbonated chamber ( $\mathrm{RH} 65 \%$ and $\mathrm{T}=20^{\circ} \mathrm{C}$ ). However, the measurement uncertainties linked to the technique have to be considered. Indeed, in TGA, the $\mathrm{CO}_{2}$ losses from $\mathrm{CaCO}_{3}$ produced during carbonation begin at a very low temperature $\left(<500^{\circ} \mathrm{C}\right)$ and they are the main losses but the water one can occur up to $600^{\circ} \mathrm{C}$ at least. These results were confirmed by coupled TGA-MS technique (see figure 13) with the crossing of the outlet gases curves of water and $\mathrm{CO}_{2}$. However, this amount of water loss between 550 and $600^{\circ} \mathrm{C}$ (after the peak of dehydration of the portlandite) is generally low, typically less than $1.5 \%$ for Ref sample. Hence, the measurement uncertainties are 4-5\% in absolute value, given in figure 12 .

In the same way as figure 8 presented the calcium loss for each phase, it was also possible to calculate the water loss for each phase, and to sum them and finally to compare with the total amount of water loss during the carbonation (orange line) which is directly obtained by TGA (see figure 14). For this calculation, it was considered that the degrading phases lost all their water molecules. Good correlations of results were observed for the CEM I, CEM I MK(10\%) and CEM I MK(25\%) samples. For the other samples, the differences were more significant. There are several hypotheses. The main one is that the amount of $\mathrm{C}-\mathrm{S}-\mathrm{H}$ water is very difficult to be separated from that one present in the porosity. In the present study, this last one was determined by drying at $40^{\circ} \mathrm{C}$ until constant mass and all the presented results take into account this amount of water. However, even at this low temperature, some of the C-S-H water was probably dried [31,45]. In addition, all bound water depends on the sorption isotherms which are themselves dependent on the type of cement used (with SCM or not). Isotherm of sorption is also not the same between a carbonated material and a non-carbonated material [45]. In conclusion, the determination of water content is hard to evaluate correctly and especially for cement paste with higher SCM content which can explain the results shown by figure 14 .

Concerning the contribution of each degraded phase to water losses, differences were showed between each cement paste (see figure 14). As expected, the contribution of portlandite decreased with the increase of the SCM proportion (comparing blue rectangles in figure 14). Indeed, more clinker in the mixes means more portlandite and therefore more water can be released by the portlandite during carbonation. Results showed that, in general, the various contributions to water losses depended on the initial phase assemblage before carbonation for each cement paste. For example, Ref CEM I MK(10\%) had a very high proportion of AFm phases (see figure 9), as these phases were strongly degraded after carbonation, there was a high contribution of these phases to the observed water loss. This was also the highest contribution compared to all cement pastes (comparing red rectangles in figure 14). The same was observed concerning the contribution of ettringite for CEM I cement paste (comparing green rectangles figure 14). With regard to C-S-H, the contribution to water loss varied greatly for the reasons mentioned in the previous paragraph.

Finally, it has been considered that these results on drying strongly depended of the carbonation conditions in chamber (temperature, $\mathrm{RH}$ and $\%$ of $\mathrm{CO}_{2}$ ) and the state of materials used here (materials cured by water during one year and dried 3 days at $60^{\circ} \mathrm{C}$ ). For example, $\mathrm{RH}$ can vary in real environmental conditions (and consequently hydric state of materials can also vary) and therefore it is difficult to reproduce these conditions in labs. 


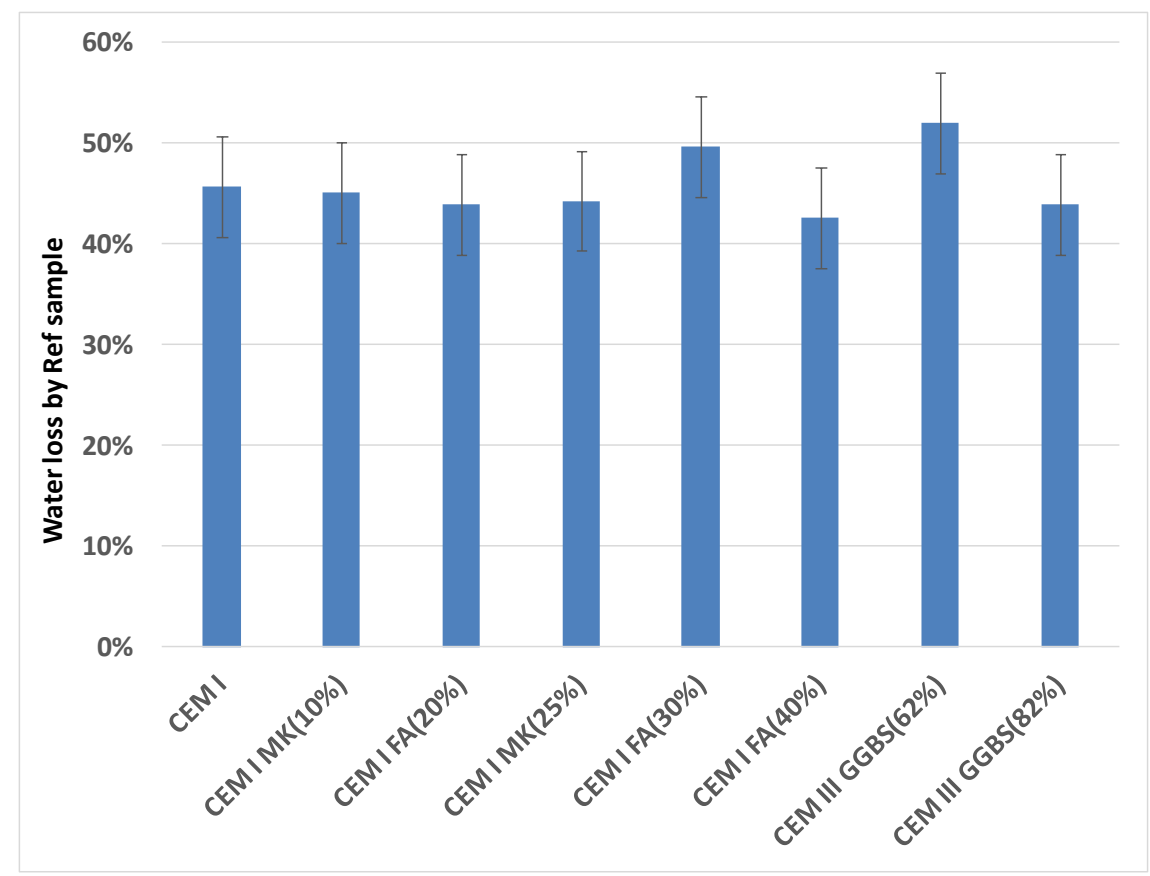

Figure 12: Water loss by Ref sample after carbonation until constant mass in chamber (at $1.5 \% \mathrm{CO}_{2}$ and $65 \%$ $\mathrm{RH})$, obtained by combined technique. TC samples were carbonated until constant mass in chamber at $1.5 \%$ $\mathrm{CO}_{2}$ and $65 \% \mathrm{RH}$ after 365 -day water curing.

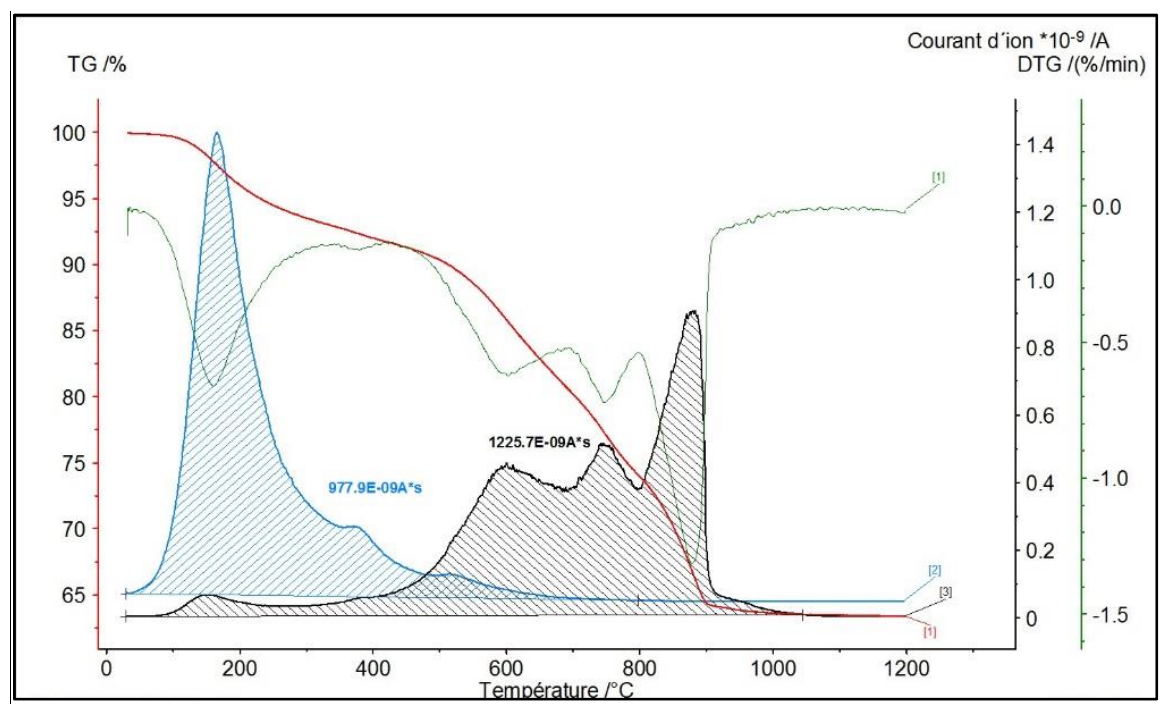

Figure 13: Example of thermodiagram obtained by TGA (TGA in red line and DTG in green line) coupled with mass spectroscopy measuring ion flux of $\mathrm{H}_{2} \mathrm{O}$ (dashed blue lines) and $\mathrm{CO}_{2}$ (dashed black line) on TC CEM I. TC samples were carbonated until constant mass in chamber at $1.5 \% \mathrm{CO}_{2}$ and $65 \% \mathrm{RH}$ after 365 -day water curing. 


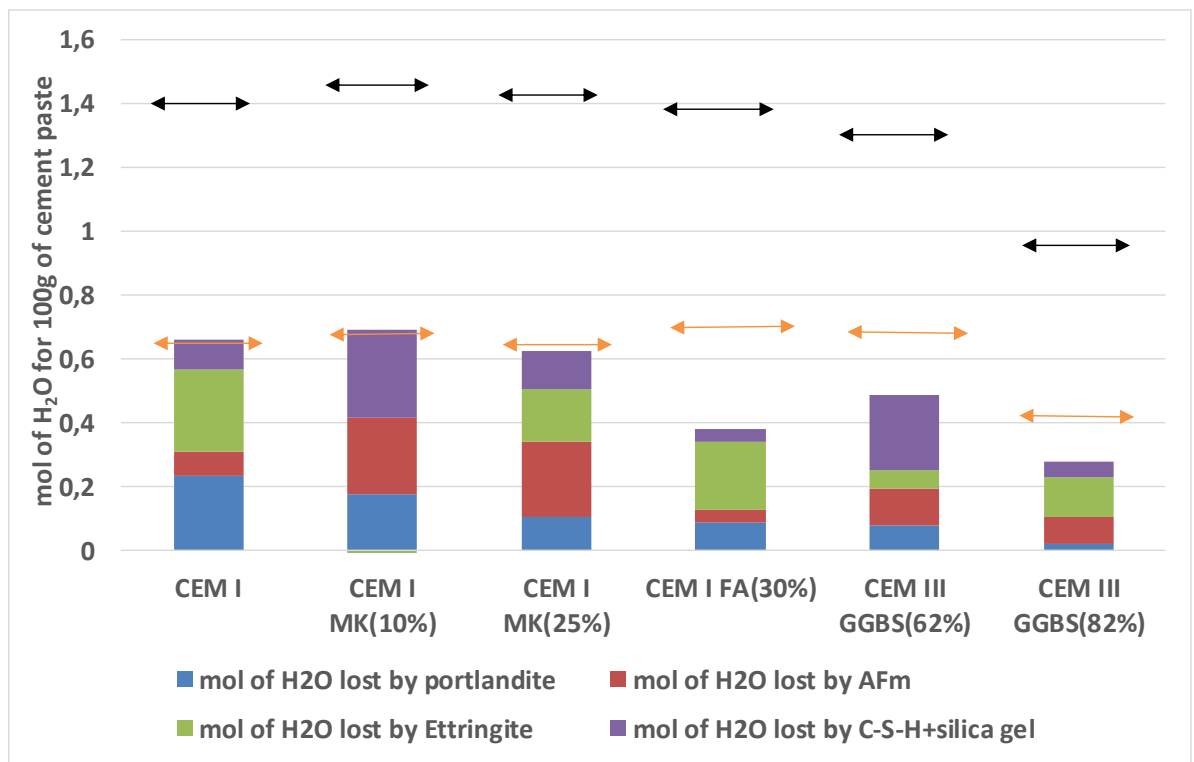

Figure 14: Molar amount of water loss by Ref sample after carbonation until constant mass in chamber (at $1.5 \%$ $\mathrm{CO}_{2}$ and $65 \% \mathrm{RH}$ ) for each hydrated phase, obtained by combined technique, and compared to the total amount of water loss obtained by TGA/DTG (orange line) and the total amount of water in Ref sample (black line) obtained by TGA/DTG. The difference between orange line and black line corresponds to the amount of water remaining chemically bound after drying and carbonation in TC sample. Here, AFm=Monocarboaluminate, Hemicarboaluminate, Monosulfoaluminate,...

\section{Conclusion}

In this paper, quantification of each mineral phase (hydrated or anhydrous) has been obtained by a combination of various techniques (XRD, DTG/TGA and ${ }^{29} \mathrm{Si}$ and ${ }^{27} \mathrm{Al}$ NMR MAS spectroscopy) before and after carbonation. The effect of supplementary cementitious materials on carbonation of the cement pastes was investigated for all cementitious phases.

For all cement pastes in this study, carbonation has a significant influence on the phase assemblage. Portlandite almost disappears and the amount of $\mathrm{C}-\mathrm{A}, \mathrm{S}-\mathrm{H}$, ettringite, AFm phases decreases. The calcium containing anhydrous phases $\left(\mathrm{C}_{2} \mathrm{~S}, \mathrm{C}_{3} \mathrm{~S}\right.$ and slag) also decreased even if the dilution effect is taken into account. The carbonation of these phases resulted in the formation of calcium carbonate and aluminosilicate phases (poor in calcium), the latter appeared mostly as amorphous and disordered phases. Decalcification of AFm phases and ettringite moved also aluminum to $\mathrm{C}-\mathrm{A}, \mathrm{S}-\mathrm{H}$ during carbonation while $\mathrm{C}-\mathrm{A}, \mathrm{S}-\mathrm{H}$ chains polymerized and a part of the water left which is due to the drying conditions in carbonation chamber. It seems that a part of aluminate substitutes to calcium keeping a locally structure of "C-S-H type".

Comparing the carbonation behavior of cement pastes containing SCM or not, revealed significant differences. Predictably, a linear relationship between the amount of $\mathrm{CaCO}_{3}$ produced and the percentage of $\mathrm{CaO}$ in the anhydrous binders was observed but this depended on the SCM type. Proportionally less calcium carbonate was formed with cement pastes containing slag. In fact, $\mathrm{C}_{2} \mathrm{~S}$ and $\mathrm{C}_{3} \mathrm{~S}$ were more reactive to the carbonation than slag and there was still a high amount of unreacted slag (containing calcium) even after one year of water curing. Consequently, it appears that for cement paste with SCM, the hydration rate has an influence on carbonation and carbonation at earlier age should be explored in future study. Decalcification of C-A,S-H appears to be complete 
only for cement pastes with high amount of MK and FA, contrary to the other cement pastes. In addition, for cement pastes with metakaolin and fly ash, a part of the aluminate phases formed TAH upon carbonation, TAH which is believed to be an amorphous/disordered aluminium hydroxide in these materials. On the opposite case, for cement paste with slag, TAH decreased after carbonation and consequently TAH seems to be more a calcium aluminate hydrate in these materials. The crystalline type of $\mathrm{CaCO}_{3}$ depend also of the initial binder. For carbonated cement paste CEM I and CEM I with fly ash or metakaolin, the 3 forms are present (calcite, aragonite and vaterite). For carbonated cement pastes with slag, there is almost just vaterite.

Finally, the carbonation of the sulfoaluminate phases raised the issue of the durability of the carbonated materials. During carbonation, ettringite releases sulphate whose future role is unknown (possible formation of expansive products). The degradation product of C-A-S-H obtained after carbonation do not have the same structure and the same surface charge and so it is more likely that this product can bind less ions (e.g. chloride, sulphate and alkalis) than uncarbonated C-A,S-H. All these points should be studied in the future focusing on the durability of carbonated materials in the case of aggressive environment (coupled attacks).

\section{Acknowledgements}

The authors are grateful to G.Platret and B.Duchesne from IFSTTAR (France) for XRD and TGA/DTG investigations, experiments, to P.Gegout and F.Barberon from Bouygues-TP for materials and for the partial funding of this study and to C. Couffe for the English proofreading of this article..

\section{References}

1] J. Cowie, F.P. Glasser. The reaction between cement and natural waters containing dissolved carbon dioxide, Advances in Cement Research 4 (1992) 119-134.

[2] V. Pollet, B. Dooms, G. Mosselmans. Prevention of corrosion of the reinforcing bars by carbonation, in French. 2007; N¹5(3) (2007).

[3] T.Q. Nguyen, J. Petkovic, P. Dangla, V. Baroghel-Bouny. Modelling of coupled ion and moisture transport in porous building materials, Construction and Building Materials 22 (2008) 2185-2195.

[4] M. Balonis, B. Lothenbach, G. Le Saout, F.P. Glasser. Impact of chloride on the mineralogy of hydrated Portland cement systems. Cement Concrete Research 40 (2010) 1009-1022.

[5] S. Rasheeduzzafar, E. Ehtesham-Hussain. Effect of cement composition on chloride binding and corrosion of reinforcing steel in concrete. Cement and Concrete Research 21 (1990) 777-794.

[6] Z. Sauman, V. Lach. Long term carbonation of the $3 \mathrm{CaO} \cdot \mathrm{Al}_{2} \mathrm{O}_{3} \cdot 6 \mathrm{H}_{2} \mathrm{O}$ and $3 \mathrm{CaO} . \mathrm{Al}_{2} \mathrm{O}_{3} \cdot \mathrm{SiO}_{2} \cdot 4 \mathrm{H}_{2} \mathrm{O}$. Cement and Concrete Research 2 (1972) 453-446.

[7] V.T. Ngala, C.L. Page. Effects of carbonation on pore structure and diffusionnal properties of hydrated cement pastes. Cement and Concrete Research 27 (1997) 995-1007.

[8] P.H.R. Borges, J.O. Costa, N.B. Milestone, C.J. Lynsdale. Carbonation of CH and C-S-H in composite cement pastes containing high amounts of BFS. Cement and Concrete Research 40 (2010) 284-292.

[9] M. Castellote, L. Fernandez, C. Andrade, C. Alonso. Chemical changes and phase analysis of OPC pastes carbonated at different $\mathrm{CO}_{2}$ concentrations. Cement and Concrete Research 42 (2009) 515-525.

[10] S. Goni, A. Guerrero. Accelerated carbonation of Friedel's salt in calcium aluminate cement paste. Cement and Concrete Research 33 (2003) 21-26.

[11] A. Morandeau, M. Thiéry, P. Dangla. Investigation of the carbonation mechanism of CH and C-S-H in terms of kinetics, microstructure changes and moisture properties. Cement and Concrete Research 56 (2014) 153170. 
[12] A. Leeman, P. Nygaard, J. Kaufman, R. Loser. Relation between carbonation resistance, mix design and exposure of mortar and concrete. Cement and Concrete Composites 62 (2015) 33-43.

[13] R. Taylor, I. Richardson, R. Brydson. Composition and microstructure of 20-year-old ordinary Portland cement-ground granulated blast-furnace slag blends containing 0 to $100 \%$ slag. Cement and Concrete Research 40 (2010) 971-983.

[14] A. Girao, I. Richardson, R. Taylor, R. Brydson. Composition, morphology and nanostructure of C-S-H in 70\% white Portland cement-30\% fly ash blends hydrated at $55^{\circ} \mathrm{C}$. Cement and Concrete Research 40 (2010) 13501359.

[15] C. Love, I. Richardson, A. Brough. Composition and structure of CSH in white portland cement -20\% metakaolin pastes hydrated at $25^{\circ} \mathrm{C}$. Cement and Concrete Research 37 (2007) 109-117.

[16] K. Scrivener, A. Nonat. Hydration of cementitious materials, present and future. Cement and Concrete Research 41 (2011) 651-665.

[17] X.Y. Wang, H.S. Lee. Modeling the hydration of concrete incorporating fly ash or slag. Cement and Concrete Research 40 (2010) 984-996.

[18] G. Villain, M. Thiery, G. Platret. Measurement of carbonation profiles in concrete: Thermogravimetry, chemical analysis and gammadensimetry. Cement and Concrete Research 37 (2007) 1182-1192.

[19] Z. Shi, B. Lothenbach, M. Rica Geiker, J. Kaufmann, A. Leemann, S. Ferreiro, J. Skibsted. Experimental studies and thermodynamic modeling of the carbonation of Portland cement, metakaolin and limestone mortars. Cement and Concrete Research 88 (2016) 60-72.

[20] B. Lu, C. Shi, G. He. Strength and Microstructure of $\mathrm{CO}_{2}$ cured low-calcium clinker. Construction and Building Materials 188 (2018) 417-423.

[21] C. Shi, M. Liu, P. He, Z. Ou. Factors affecting kinetics of $\mathrm{CO}_{2}$ curing of concrete. Journal of Sustainable Cement-based Materials, 1 (2012) 24-33.

[22] G. Engelhardt, D. Michel, High resolution ${ }^{29} \mathrm{Si}$ NMR of silicates and Zeolites, Wiley, New York, 1987.

[23] M.R. Jones, D.E. Macphee, J.A. Chudek, G. Hunter, R. Lannegrand, R. Talero, S.N. Scrimgeour. ${ }^{27}$ Al MAS NMR of AFm and AFt phases and the formation of Friedel's salt. Cement and Concrete Research 33 (2003) 177182.

[24] G.K. Sun, J.F. Young, R.J. Kirkpatrick. The role of Al in C-S-H: NMR, XRD, and compositional results for precipitated samples. Cement and Concrete Research 36 (2006) 18-29.

[25] M.D. Andersen, H.J. Jakobsen, J. Skibsted. A new aluminium-hydrate species in hydrated Portland cements characterized by 27Al and 29Si MAS NMR spectroscopy. Cement and Concrete Research 36 (2006) 3-17

[26] J. Skibsted, E. Henderson, H.J. Jakobsen. Characterization of calcium aluminate phases in cements by ${ }^{27} \mathrm{Al}$ MAS NMR spectroscopy. Inorganic Chemistry 32 (1993) 1013-1027.

[27] J.J. Beaudoin, H. Dramé, R. Laila, R. Alizadeh. Formation and properties of C-S-H-PEG nano-structures, Materials and Structures 42 (2009) 1003-1014.

[28] J.J. Thomas, A.J. Allen, H. Jennings. Density and water content of nanoscale solid C-S-H formed in alkaliactivated slag (AAS) paste and implications for chemical shrinkage. Cement and Concrete Research 42 (2012) 377-383

[29] I.G. Richardson. The nature of C-S-H in hardened cements. Cement and Concrete Research 29 (1999) 11311147.

[30] D. Massiot F. Fayon, M. Capron, I. King, S. Le Calvé, B. Alonso, J.O. Durand, B. Bujoli, Z. Gan, G. Hoatson. Modelling one and two-dimensional solid-state NMR spectra. Magnetic Resonance in Chemistry 40 (2002) 7076.

[31] M. Saillio, V. Baroghel-Bouny, M. Bertin, S. Pradelle, J. Vincent. Phase assemblage of cement pastes with SCM at different ages. Construction and Building Materials 224 (2019) 144-157.

[32] Y.A.Villagrán-Zaccardi, H.Egüez-Alava, K.De Buysser, E. Gruyaert. Calibrated quantitative thermogravimetric analysisfor the determination of portlandite and calcite contentin hydrated cementitious systems. Materials and Structure 50 (2017) 165-179.

[33] M. Peter, A. Muntean, S. Meier, M. Bohm. Competition of several carbonation reactions in concrete: a parametric study. Cement and Concrete Research 38 (2008) 1385-1393. 
[34] L.J. Parott, Review of carbonation of concrete, British Cement Association, Londres, 1987.

[35] W. Taylor, Cement chemistry, academic press, London, 1997.

[36] B. Dilnesa, B. Lothenbach, G. Le Saout, G. Renaudin, A. Mesbah, Y. Filinchuck. Iron in carbonate containing AFm phases. Cement and Concrete Research 41 (2011) 311-323.

[37] C. Utton, E. Gallucci, J. Hill, N. Milestone. Interaction between BaCO3 and OPC/BFS composite cements at $20^{\circ} \mathrm{C}$ and $60^{\circ} \mathrm{C}$. Cement and Concrete research 41 (2011) 236-243.

[38] M. Saillio, V. Baroghel-Bouny. Chloride binding in sound and carbonated cementitious materials with various types of binder. Construction and Building Materials 68 (2014) 82-91.

[39] M. Saillio, V. Baroghel-Bouny, S. Pradelle. Various durability aspects of calcined Kaolin-Blended Portland cement pastes and concretes. Proceedings of Calcined clays for sustainable concrete, RILEM Bookseries, Lausane, 2015, 491-499.

[40] S. Monkman, P. Kenward, G. Dipple, M. MacDonald, M. Raudsepp. Activation of cement hydration with carbon dioxide. Journal of Sustainable Cement-based Materials 7 (2018) 160-181.

[41]N. Rafai, H. Hornain, G. Villain, V. Baroghel-Bouny, G. Platret, T. Chaussadent. Comparison and validity of the carbonation methods in french. RFGC 6 (2002) 251-274.

[42] K. De Weerdt, G. Plusquellec, A. Belda Revert, M.R. Geiker, B. Lothenbach. Effect of carbonation on the pore solution of mortar. Cement and Concrete Research 118 (2019) 38-56.

[43]C. Tai, S. Chen. Nucleation, agglomeration and crystal morphology of calcium carbonate. AIChE Journal 41 (1995) 68-77.

[44] E. Drouet. Impact of temperature on carbonation process of cementitious materials, in French, Ph.D Thesis, Cachan, 2010.

[45] M. Bertin. Impact of drying at a young age on the carbonation of cementitious materials with supplementary cementitious materials, in French, Ph.D Thesis, Marne La Vallée, 2017.

[46] W. Liu, Y. Li, S. Lin, L. Tang, Z. Dong, F. Xing, B. Dong, S. Hong. Changes in chemical phases and microscopic characteristics of fly ash blended cement pastes in different $\mathrm{CO} 2$ concentrations. Construction and Building Materials 257 (2020) 119598.

[47]C. Hargis, B. Lothenbach, C. Müller, F. Winnefeld. Carbonation of calcium sulfoaluminate mortars. Cement and Concrete Composites 80 (2017) 123e134.

[48]T. Nishikawa, K. Suzuki, S. Ito. Decomposition of synthetisized ettringite by carbonation. Cement and Concrete Research 22 (1992) 6-14.

[49]J. Plank, M. Zhang-Preße, N.P. Ivleva, R. Niessner. Stability of single phase C3A hydrates against pressurized CO2. Construction and Building Materials 122 (2016) 426-434.

[50]D. Gastaldi, F. Bertola, F. Canonico, L.Buzzi, S. Mutke, Sara Irico, G. Paul, L. Marchese, E. Boccaleri. A chemical/mineralogical investigation of the behavior of sulfoaluminate binders submitted to accelerated carbonation. Cement and Concrete Research 109 (2018) 30-41.

[51]M. Perez, T. Vazquez, F. Trivino. Study of stabilized phases in high lumina cement mortars part I hydration at elevated temperatura followed by carbonation. Cement and Concrete research 13 (1983) 759-770.

[52]R.D. Blenkinsop, B.R. Currell, H.G. Midgley, J.R. Parsonage. The carbonation of high alumina cement part I. Cement and Concrete Resarch 15 (1985) 276-284.

[53]R.D. Blenkinsop, B.R. Currell, H.G. Midgley, J.R. Parsonage. The carbonation of high alumina cement part II. Cement and Concrete Resarch 15 (1985) 385-390.

[54]L. Fernández-Carrasco, J. Rius, Carles Miravitlles. Supercritical carbonation of calcium aluminate cement. Cement and Concrete Research 38 (2008) 1033-1037.

[55]S. Park, J. Jang, H. Son, H. Lee. Stable conversion of metastable hydrates in calcium aluminate cement by early carbonation curing. Journal of $\mathrm{CO}_{2}$ Utilization 21 (2017) 224-226.

[56]N. Hyvert, A. Sellier, F. Duprat, P. Rougeau, P. Francisco. Dependency of C-S-H carbonation rate on CO2 pressure to explain transition from accelerated tests to natural carbonation. Cement and Concrete Research 40 (2010) 1582-1589.

[57]M. Frías, S. Goñi. Accelerated carbonation effect on behaviour of ternary Portland cements. Composites: Part B 48 (2013) 122-128.

[58]B. Chen, M. Horgnies, B. Huet, V. Morin, K. Johannes, F. Kuznik. Comparative kinetics study on carbonation of ettringite and meta-ettringite based materials. Cement and Concrete Research 137 (2020) 106209. 
[59]J. Herterich. Microstructure and phase assemblage of low-clinker cements during early stages of carbonation, PhD Thesis, University of Leeds, 2017.

[60] T. Sevelsted, J. Skibsted. Carbonation of C-S-H and C-A-S-H samples studied by ${ }^{13} \mathrm{C},{ }^{27} \mathrm{Al}$ and ${ }^{29} \mathrm{Si}$ MAS NMR spectroscopy. Cement and Concrete Research 71 (2015) 56-65. 


\section{Appendix}

NMR results are obtained from the deconvolution parameters presented in table 4 and 5 . The following annotation was used:

- 7766: CEM I

- 7809: CEM I MK(10\%)

- 7885: CEM I MK(25\%)

- 8020: CEM I FA(20\%)

- 7808: CEM I FA(30\%)

- 8040: CEM I FA(40\%)

- 7780: CEM III GGBS(62\%)

- 7781: CEM III GGBS(82\%) 
Table 4: Parameters of ${ }^{27} \mathrm{AI}$ MAS NMR spectra deconvolution used in DMFit. Details of parameters and their meaning can be found in [18-22][40].

\begin{tabular}{|c|c|c|c|c|c|c|c|c|c|c|c|c|c|}
\hline \multirow{2}{*}{\multicolumn{2}{|c|}{$\begin{array}{c}\text { Peak } \\
\text { Samples }\end{array}$}} & \multicolumn{2}{|c|}{$\begin{array}{c}\text { AFt } \\
(\mathrm{Xg}=0)\end{array}$} & \multicolumn{2}{|c|}{$\begin{array}{c}\mathrm{AFm} \\
(\mathrm{Cz} ; \mathrm{FWHH}=2.2 ; \mathrm{d}=5)\end{array}$} & \multicolumn{2}{|c|}{$\begin{array}{c}\text { TAH } \\
(\mathrm{Cz} ; \mathrm{FWHH}=2.2 ; \mathrm{d}=5)\end{array}$} & \multicolumn{2}{|c|}{$\begin{array}{c}\mathrm{Al}(\mathrm{IV})(1) \\
(\mathrm{Xg}=0)\end{array}$} & \multicolumn{2}{|c|}{$\begin{array}{c}\mathrm{Al}(\mathrm{IV})(2) \\
(\mathrm{Xg}=0)\end{array}$} & \multicolumn{2}{|c|}{$\begin{array}{c}\mathrm{Al}(\mathrm{V}) \\
(\mathrm{Xg}=0) \\
\end{array}$} \\
\hline & & $\begin{array}{c}\text { Position } \\
\text { (ppm) }\end{array}$ & $\begin{array}{l}\text { FWHH } \\
(\mathrm{ppm})\end{array}$ & $\begin{array}{l}\text { Position } \\
\text { (ppm) }\end{array}$ & $\begin{array}{c}\text { EmAu / } \\
\text { nuQ }\end{array}$ & $\begin{array}{c}\text { Position } \\
\text { (ppm) }\end{array}$ & $\begin{array}{c}\text { EmAu / } \\
\text { nuQ }\end{array}$ & $\begin{array}{l}\text { Position } \\
\text { (ppm) }\end{array}$ & $\begin{array}{l}\text { FWHH } \\
(\mathrm{ppm})\end{array}$ & $\begin{array}{l}\text { Position } \\
\text { (ppm) }\end{array}$ & $\begin{array}{l}\text { FWHH } \\
\text { (ppm) }\end{array}$ & $\begin{array}{l}\text { Position } \\
\text { (ppm) }\end{array}$ & $\begin{array}{l}\text { FWHH } \\
(\mathrm{ppm})\end{array}$ \\
\hline \multirow{8}{*}{ REF } & 7766 & 13.2 & 3.0 & 9.8 & $\begin{array}{c}2087 / \\
266\end{array}$ & 6.5 & $100 / 530$ & 70.0 & 7.9 & 62.2 & 5.3 & 34.2 & 9.6 \\
\hline & 7809 & 13.2 & 3.0 & 9.6 & $\begin{array}{c}3305 / \\
202 \\
\end{array}$ & 6.7 & $100 / 529$ & 70.0 & 9.0 & 63.0 & 10.0 & 34.2 & 29.0 \\
\hline & 7885 & 13.2 & 3.0 & 9.9 & $\begin{array}{c}3305 / \\
202 \\
\end{array}$ & 6.7 & $100 / 529$ & 70.0 & 9.0 & 62.0 & 10.0 & 34.0 & 29.0 \\
\hline & 8020 & 13.5 & 3.3 & 10.4 & $\begin{array}{c}1200 / \\
300\end{array}$ & 6.7 & $100 / 600$ & 69.6 & 9.0 & 59.9 & 10.0 & 35.0 & 20.0 \\
\hline & 7808 & 13.2 & 3.3 & 11.0 & $\begin{array}{c}1900 / \\
243 \\
\end{array}$ & 6.5 & 223 / 632 & 70.0 & 12.0 & 60.0 & 10.0 & 34.4 & 20.0 \\
\hline & 8040 & 13.8 & 3.3 & 10.6 & $\begin{array}{c}1400 / \\
320 \\
\end{array}$ & 6.7 & $100 / 600$ & 69.6 & 13.0 & 59.9 & 10.0 & 35.0 & 20.0 \\
\hline & 7780 & 13.2 & 3.3 & 10.2 & $\begin{array}{c}1900 / \\
267\end{array}$ & 6.5 & 223 / 632 & 70.0 & 7.0 & 62.0 & 20.0 & 34.4 & 20.0 \\
\hline & 7781 & 13.3 & 3.3 & 10.4 & $\begin{array}{c}1800 / \\
254\end{array}$ & 6.5 & $100 / 476$ & 70.0 & 7.0 & 61.0 & 20.0 & 35.5 & 23.0 \\
\hline \multirow{8}{*}{ TC } & 7766 & 13.4 & 3.0 & 10.2 & $\begin{array}{c}838 / \\
307 \\
\end{array}$ & 6.7 & $150 / 740$ & 69.0 & 7.0 & 57.9 & 12.0 & 34.2 & 15.0 \\
\hline & 7809 & 13.2 & 3.0 & 10.0 & $\begin{array}{c}3305 / \\
202 \\
\end{array}$ & 6.7 & $100 / 529$ & 70.0 & 9.0 & 57.0 & 12.0 & 34.0 & 29.0 \\
\hline & 7885 & 13.2 & 3.0 & 10.4 & $\begin{array}{c}2000 / \\
275\end{array}$ & 5.2 & $100 / 600$ & 70.0 & 9.0 & 60.0 & 15.0 & 34.0 & 29.0 \\
\hline & 8020 & 13.5 & 3.3 & 10.4 & $\begin{array}{c}1200 / \\
300\end{array}$ & 6.7 & $100 / 600$ & 69.6 & 9.0 & 56.1 & 12.0 & 35.0 & 20.0 \\
\hline & 7808 & 13.2 & 3.3 & 10.4 & $\begin{array}{c}3305 / \\
202 \\
\end{array}$ & 6.7 & $100 / 529$ & 70.0 & 7.0 & 57.0 & 12.0 & 35.7 & 29.1 \\
\hline & 8040 & 13.8 & 3.3 & 10.6 & $\begin{array}{c}1400 / \\
320\end{array}$ & 6.7 & $100 / 600$ & 69.6 & 9.0 & 56.1 & 12.0 & 35.0 & 20.0 \\
\hline & 7780 & 13.2 & 3.3 & 10.1 & $\begin{array}{c}3305 / \\
232 \\
\end{array}$ & 6.7 & $100 / 529$ & 70.0 & 7.0 & 56.4 & 11.7 & 34.2 & 20.0 \\
\hline & 7781 & 13.5 & 3.3 & 10.6 & $\begin{array}{c}2200 / \\
265\end{array}$ & 6.7 & $100 / 476$ & 70.0 & 7.0 & 56.4 & 12.0 & 34.0 & 23.0 \\
\hline
\end{tabular}


Table 5: Parameters of ${ }^{29} \mathrm{Si}$ MAS NMR spectra deconvolution used in DMFit. Details of parameters and their meaning can be found in [18-22][40]. In addition, there are also peaks for GGBS (Q ${ }^{0}$ (slag) -77.2 and -77.8 ppm; FWHH 2 and 8 ppm) and for FA ( $Q^{4}(F A)-93.4$ and -108.2 ppm ; FWHH 8 and 8 ppm). For MK, peak is considered negligible (all MK are supposed to react).

\begin{tabular}{|c|c|c|c|c|c|c|c|c|c|c|c|c|c|c|c|c|c|}
\hline \multirow{2}{*}{\multicolumn{2}{|c|}{$\begin{array}{c}\text { Peak } \\
\text { Samples }\end{array}$}} & \multicolumn{2}{|c|}{$\begin{array}{c}C_{3} S \\
(X g=0.5)\end{array}$} & \multicolumn{2}{|c|}{$\begin{array}{c}\mathrm{C}_{2} \mathrm{~S} \\
(\mathrm{Xg}=0.5)\end{array}$} & \multicolumn{2}{|c|}{$\begin{array}{c}C_{3} S \\
(X g=0.5)\end{array}$} & \multicolumn{2}{|c|}{$\begin{array}{c}Q^{1} \\
(X g=0.5)\end{array}$} & \multicolumn{2}{|c|}{$\begin{array}{c}Q^{2}(1 \mathrm{Al}) \\
\mathrm{Q}^{2} \mathrm{~b} \\
(\mathrm{Xg}=0.5)\end{array}$} & \multicolumn{2}{|c|}{$\begin{array}{c}Q^{2} p \\
(X g=0.5)\end{array}$} & \multicolumn{2}{|c|}{$\begin{array}{c}Q^{3} \\
(X g=0.5)\end{array}$} & \multicolumn{2}{|c|}{$\begin{array}{c}Q^{4} \\
(X g=0.5)\end{array}$} \\
\hline & & $\begin{array}{c}\text { Position } \\
\text { (ppm) }\end{array}$ & $\begin{array}{l}\text { FWHH } \\
\text { (ppm) }\end{array}$ & $\begin{array}{c}\text { Position } \\
\text { (ppm) }\end{array}$ & $\begin{array}{l}\text { FWHH } \\
\text { (ppm) }\end{array}$ & $\begin{array}{c}\text { Position } \\
\text { (ppm) }\end{array}$ & $\begin{array}{l}\text { FWHH } \\
\text { (ppm) }\end{array}$ & $\begin{array}{c}\text { Position } \\
\text { (ppm) }\end{array}$ & $\begin{array}{l}\text { FWHH } \\
\text { (ppm) }\end{array}$ & $\begin{array}{c}\text { Position } \\
\text { (ppm) }\end{array}$ & $\begin{array}{l}\text { FWHH } \\
\text { (ppm) }\end{array}$ & $\begin{array}{c}\text { Position } \\
\text { (ppm) }\end{array}$ & $\begin{array}{l}\text { FWHH } \\
\text { (ppm) }\end{array}$ & $\begin{array}{c}\text { Position } \\
\text { (ppm) }\end{array}$ & $\begin{array}{l}\text { FWHH } \\
\text { (ppm) }\end{array}$ & $\begin{array}{c}\text { Position } \\
\text { (ppm) }\end{array}$ & $\begin{array}{l}\text { FWHF } \\
\text { (ppm) }\end{array}$ \\
\hline \multirow{6}{*}{ REF } & 7766 & -69.1 & 3.0 & -71.7 & 3.0 & -73.5 & 4.0 & -79.6 & 6.0 & -82.1 & 3.0 & -85.7 & 6.0 & -91.5 & 8.0 & -110.0 & 20.0 \\
\hline & 7809 & -69.1 & 3.0 & -71.7 & 3.0 & -73.5 & 4.0 & -79.6 & 6.0 & -82.1 & 3.0 & -85.7 & 6.0 & -91.5 & 8.0 & -107.0 & 20.0 \\
\hline & 7885 & -68.7 & 3.0 & -71.2 & 3.0 & -73.0 & 4.0 & -79.1 & 6.0 & -81.6 & 3.0 & -85.1 & 6.0 & -90.9 & 8.0 & -103.3 & 20.0 \\
\hline & 7808 & -68.7 & 3.0 & -71.2 & 3.0 & -73.0 & 4.0 & -79.1 & 6.0 & -81.6 & 3.0 & -85.1 & 6.0 & -90.9 & 8.0 & -106.3 & 20.0 \\
\hline & 7780 & -69.3 & 2.9 & -71.7 & 3.0 & -73.5 & 4.0 & -79.6 & 6.0 & -82.1 & 3.0 & -86.0 & 6.0 & -91.1 & 8.0 & -110.0 & 20.0 \\
\hline & 7781 & -69.3 & 2.9 & -71.7 & 3.0 & -73.5 & 4.0 & -79.6 & 6.0 & -82.1 & 3.0 & -86.0 & 6.0 & -91.1 & 8.0 & -110.0 & 20.0 \\
\hline \multirow{6}{*}{ TC } & 7766 & -69.1 & 3.0 & -71.7 & 3.0 & -73.5 & 4.0 & -79.6 & 6.0 & -82.1 & 3.0 & -85.7 & 6.0 & -91.5 & 8.0 & -110.0 & 20.0 \\
\hline & 7809 & -69.1 & 3.0 & -71.7 & 3.0 & -73.5 & 4.0 & -79.6 & 6.0 & -82.1 & 3.0 & -85.7 & 6.0 & -91.5 & 8.0 & -107.0 & 20.0 \\
\hline & 7885 & -68.7 & 3.0 & -71.2 & 3.0 & -73.0 & 4.0 & -79.1 & 6.0 & -81.6 & 3.0 & -85.1 & 6.0 & -90.9 & 8.0 & -103.3 & 20.0 \\
\hline & 7808 & -68.7 & 3.0 & -71.2 & 3.0 & -73.0 & 4.0 & -79.1 & 6.0 & -81.6 & 3.0 & -85.1 & 6.0 & -90.9 & 8.0 & -106.3 & 20.0 \\
\hline & 7780 & -69.3 & 2.9 & $\begin{array}{l}-71.7 \\
\end{array}$ & 3.0 & -73.5 & 4.0 & -79.6 & 6.0 & -82.1 & 3.0 & -86.0 & 6.0 & -91.1 & 8.0 & -110 & 20.0 \\
\hline & 7781 & -69.3 & 2.9 & -71.7 & 3.0 & -73.5 & 4.0 & -79.6 & 6.0 & -82.1 & 3.0 & -86.0 & 6.0 & -91.1 & 8.0 & -110 & 20.0 \\
\hline
\end{tabular}

